\title{
Fire safety Assessment of Open Wide Gangway Underground Trains in Tunnels Using Coupled Fire and Evacuation Simulation
}

\author{
E.R.Galea, Z. Wang, F. Jia, P.J. Lawrence and J. Ewer \\ Fire Safety Engineering Group, University of Greenwich, 30 Park Row, Greenwich, UK
}

\begin{abstract}
A new type of train configuration, known as Open Wide Gangway (OWG) is becoming popular, particularly in underground environments. Previous fire modelling analysis demonstrated that the OWG configuration was considered safe as or safer than conventional configurations as it reduced the likelihood of flashover. However, these studies have ignored the impact on evacuation of the spread of fire effluent to non-fire cars. Here we explore the fire safety offered by conventional and OWG configurations using coupled fire and evacuation modelling techniques. Two tunnel train situations are considered; one in which the car side doors are available for evacuation (train in a wide tunnel) and the other in which only the end cab doors are available (train in a narrow tunnel). Two population configurations are considered, fully and half loaded. Two ignition sources are also considered, one representing an accidental fire and the other an arson fire. The analysis demonstrates that while the OWG configuration may produce improved fire performance in the car of fire origin compared to the conventional configuration, if the interaction of the fire effluent with the evacuating passengers is considered, the OWG configuration results in a significantly greater number of casualties in virtually all the scenarios considered.
\end{abstract}

Key words: Open wide gangway, underground train fire, tunnel fire, Fire modelling, Evacuation modelling.

\section{INTRODUCTION}

Situations requiring a rapid evacuation of passenger trains are rare however, the most critical incidents are those involving fire [1]. Even in fire situations, it may not be necessary to evacuate from the train, the movement of passengers to a place of relative safety on the train being preferred to evacuation to the track side. In conventional trains, passenger cars (also referred to as carriages) are typically separated by internal doors (ID), which while usually closed, allow passengers to move between the cars. In the event of an internal fire, these doors provide passengers with some degree of protection from the developing fire and the fire effluent as they act as a barrier, if closed, to the spreading fire effluent. Passengers can move from the car of fire origin to the neighbouring cars, closing the doors behind them. For scenarios involving over-ground trains, should an evacuation be required, passengers can exit the train through the carriage side doors down to the track side. In underground tunnel environments the situation is more complex and is dependent on the geometry of the tunnel. If the train is in a wide tunnel, evacuation can occur from the car side doors directly to the track side as in over-ground trains [2]. However, if the train is in a narrow tunnel, as may be found in some older underground systems, evacuation from the car side doors may be impossible as there is insufficient room for passengers to safely exit the train and walk 
alongside the train. In this case, passengers must move through the train from car to car until reaching the drivers cab or end cab, which allows egress to the track side [2].

Open wide gangway $(\mathrm{OWG})$ trains are a relatively new concept in passenger train design that is being introduced in many over-ground and underground rail networks worldwide. OWG trains consist of what is essentially one long passenger compartment, with no partitions or doors between cars. The attraction of OWG trains is that they can accommodate more passengers than the conventional passenger train configuration; they facilitate more efficient boarding/disembarkation at stations and because of their open design, provide a better security environment for passengers. However, as there is no longer a barrier between the cars to prevent the spread of fire and fire effluent, the concept of a place of relative safety on board is compromised. In fire situations, the absence of inter-car doors in OWG trains could potentially expose passengers in non-fire cars to life threatening fire hazards sooner than would be the case in the conventional configuration, especially in situations where the end cab doors are the only means available for egress to the track side.

The fire safety issues related to the OWG trains are to a certain degree not in conformance with the design principles for underground trains in UK [2], which specifies that each car should be in effect a fire resisting box, with fire resisting floors and doors between cars. Furthermore, not much research effort appears to have been invested into this important topic. Chiam [3] has numerically simulated fire growth and flame spread in Singapore Circle line OWG trains under forced ventilation conditions. In his study, flashover was not observed with ignition sources representing arson fires. With the same train interior materials as in Chiam's work, Ting et al [4] has further confirmed that, "the use of flame retardant, BS6853 Cat 1a compliant materials suitably avoids flashover within the cabin and prevents the uncontrolled spread of fire to adjacent cars".

Their analyses have assumed that the primary impact on life safety is the occurrence of flashover. However, this is not necessarily the case as the spreading fire effluent may also have a significant impact on life safety. Thus it is important to establish whether or not the spreading fire effluent will impact passenger evacuation and survivability even if a flashover does not occur or even if the fire is not sustainable. In this study, this issue is explored through numerical simulations using the coupled fire and evacuation simulation technique with the SMARTFIRE [5] CFD fire simulation software and the railEXODUS [1, 6] evacuation simulation tool. In this paper, sixteen evacuation scenarios corresponding to ten fire scenarios involving a train in a tunnel with various car separation configurations, available train exits for evacuation, population loads and ignition sources are defined and investigated using the coupled fire and evacuation analysis.

\section{FIRE AND EVACUATION SCENARIOS}

The base configuration used in this study is loosely based on the four-car Class 378 train, which is in use on London's underground system [7]. In this study, two different car separation configurations are considered, $\mathrm{OWG}$ and conventional internal doors. As seen in Fig. 1, the conventional internal doorway is assumed to be $0.8 \mathrm{~m}$ wide and $1.9 \mathrm{~m}$ high. The dimensions of the connecting region between OWG cars are; $1.2 \mathrm{~m}$ wide and $1.9 \mathrm{~m}$ high. These dimensions are approximations to the measurements of existing cars, and are not intended to be exact measurements for any particular train. 

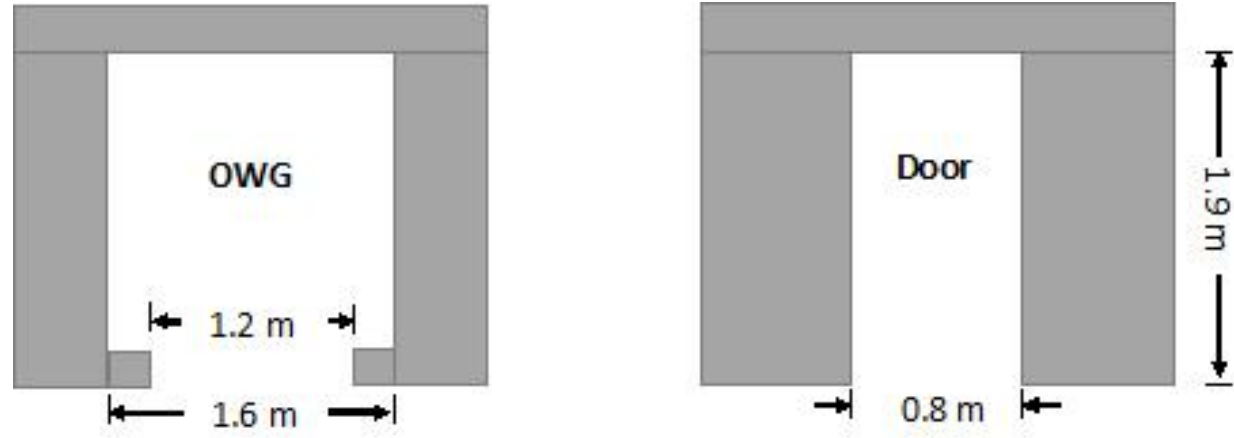

Fig. 1. Sizes of OWG and conventional internal door.

Train fires usually start with a small primary fire, the ignition source, and subsequently spread to car interior materials such as seat foam, wall panels and floor carpet etc. The resulting fire effluent can spread from car to car impacting the safety and evacuation of passengers. The nature of the ignition source is an important factor in determining whether or not the fire will grow to consume train materials and the speed of the subsequent developing fire. To specify the fire scenario it is therefore necessary to first define appropriate fire ignition sources. Two ignition sources are considered in this study. One is representative of a slowly developing luggage fire and the other is intended to represent a fast growth luggage fire. The heat release rates (HRR) of the two ignition sources are depicted in Fig. 2, one is intended to represent the development of an accidental fire and the other is intended to represent the development of a deliberate arson fire. An ignition source of between 25 and $200 \mathrm{~kW}$ is necessary to promote a significant fire spread in materials typically found on modern trains [8]. Therefore, both ignition sources have a peak HRR in excess of $500 \mathrm{~kW}$ as shown in Fig. 2. The first ignition source, called "accidental" in this study, has a fire growth rate identical to that used by Ting et al [4] to investigate the spread of fire between cars in OWG trains. However, the most common train fires are started by arson, which account for nearly $70 \%$ of total train fires [3]. Fire accelerants are often involved in arson fires. An example is the Daegu subway fire on February 18, 2003, South Korea, killed at least 192 people and injured at least 148, in which 4 litres of volatile material were used by the arsonist [9]. Fire accelerants such as gasoline will enable a fire to reach its peak HRR as early as 20 seconds for common flooring materials [10]. This second ignition source, the fast growth luggage fire, is used to represent a deliberately started fire as may occur in an arson or terrorist attack. The two ignition sources shown in Fig. 2 are compliant with BS 6853, in which a large ignition source is suggested in the order of $100 \mathrm{~kW} \mathrm{[2].}$

Given the two ignition sources, a total of sixteen evacuation scenarios, corresponding to ten fire scenarios, are defined for investigation in this study. These consist of combinations of the car separation configurations i.e. OWG and ID configuration, population loading i.e. fully loaded with 715 passengers and half loading with 360 passengers and exit door availability i.e. side doors or end doors. In each scenario, the train is assumed to be in a tunnel and not at the station platform. This makes evacuation more challenging as passengers must descend approximately $1 \mathrm{~m}$ to the track side rather than simply step out onto the platform.

Table 1 lists all the scenarios investigated. The full population load corresponds to a density of approximate 5 persons $/ \mathrm{m}^{2}$, which is the observed maximum standing capacity for rolling stock on London Underground [11]. Scenarios S1-S4 use the accidental fire as the ignition source. In Scenarios 1 and 2 passengers use the car side doors for evacuation, with Scenario 1 involving the OWG configuration while Scenario 2 involves the ID configuration. Furthermore, in Scenario 2, the internal doors between the cars remain closed throughout the 
simulation as passengers evacuate via the side doors. In Scenarios 3 and 4 only the end cab doors are available for evacuation, with Scenario 3 involving the OWG configuration and Scenario 4 involves the ID configuration. In Scenario 4, the internal doors are all open at the start of the simulation as passengers attempt to move between cars and are closed after the last survivor passes through the door. In addition, the ' $a$ ' scenarios involve the maximum passenger load while the ' $b$ ' scenarios involve half the maximum passenger load. As the number of passengers in an evacuation scenario will impact the door closure times, this will in turn impact the ventilation within the train and hence the fire development. Thus the fire scenarios associated with the evacuation Scenarios $4 \mathrm{a}$ and $4 \mathrm{~b}$ (scenarios involving ID configuration in which only the end cab doors are available for evacuation) are different due to the use of different population loads. Scenarios S5-S8 are the same as Scenarios S1-S4 but have the arson fire as the ignition source.

In all the scenarios considered the train is assumed to be within a tunnel. Passengers are expected to evacuate to the ground when using the car end doors (S3, S4, S7, S8) or to a side walkway when using the side doors (S1, S2, S5, S6). The fire effluent spreads into the tunnel from the rail cars via the open doors. However, forced ventilation within the tunnel is not considered and it is further assumed that there is no natural air movement at the start of the simulation.

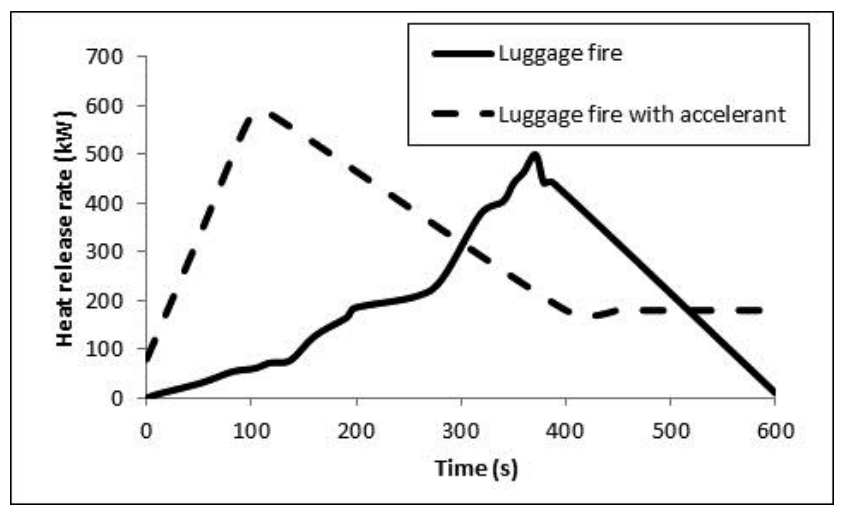

Fig. 2. HRRs of luggage fires as ignition sources of the accident fire and the arson fire.

Table 1. Fire and evacuation scenarios.

\begin{tabular}{|c|c|c|c|c|c|}
\hline $\begin{array}{c}\text { Fire } \\
\text { Scenario } \\
\end{array}$ & $\begin{array}{c}\text { Evacuation } \\
\text { Scenario } \\
\end{array}$ & Car separation & $\begin{array}{c}\text { Opening exits for } \\
\text { evacuation }\end{array}$ & $\begin{array}{c}\text { Population } \\
\text { load }\end{array}$ & Fire \\
\hline \multirow[t]{2}{*}{ S1 } & S1a & OWG & Side passenger doors & Full & \multirow{8}{*}{$\begin{array}{l}\text { Accidental } \\
\text { fire }\end{array}$} \\
\hline & S1b & OWG & Side passenger doors & Half & \\
\hline \multirow[t]{2}{*}{ S2 } & S2a & ID & Side passenger doors & Full & \\
\hline & S2b & ID & Side passenger doors & Half & \\
\hline \multirow[t]{2}{*}{ S3 } & S3a & OWG & End Cab doors & Full & \\
\hline & S3b & OWG & End Cab doors & Half & \\
\hline $\mathrm{S} 4 \mathrm{a}$ & $\mathrm{S} 4 \mathrm{a}$ & $\mathrm{ID}^{\mathrm{a}}$ & End Cab doors & Full & \\
\hline S4b & S4b & $\mathrm{ID}^{\mathrm{a}}$ & End Cab doors & Half & \\
\hline \multirow[t]{2}{*}{ S5 } & S5a & OWG & Side passenger doors & Full & \multirow{8}{*}{ Arson fire } \\
\hline & S5b & OWG & Side passenger doors & Half & \\
\hline \multirow[t]{2}{*}{ S6 } & S6a & ID & Side passenger doors & Full & \\
\hline & S6b & ID & Side passenger doors & Half & \\
\hline \multirow[t]{2}{*}{ S7 } & S7a & OWG & End Cab doors & Full & \\
\hline & S7b & OWG & End Cab doors & Half & \\
\hline S8a & S8a & $\mathrm{ID}^{\mathrm{a}}$ & End Cab doors & Full & \\
\hline S8b & S8b & $\mathrm{ID}^{\mathrm{a}}$ & End Cab doors & Half & \\
\hline
\end{tabular}

${ }^{a}$ The internal doors between cars are shut after the last survivor passes through the doorway. 


\section{COUPLED FIRE AND EVACUATION ANALYSIS TECHNIQUE}

In this section, the coupled fire and evacuation simulation technique is described using the fire engineering tools, SMARTFIRE and railEXODUS. The SMARTFIRE V4.1 [5] software is used as the base model to perform the fire simulations in this study. The CFD engine in SMARTFIRE has many physics features that are required for fire field modelling, such as the multiple ray radiation model, the volumetric heat release model, the gaseous combustion model, smoke model, toxicity model, flame spread model and k-epsilon turbulence model. The flame spread model [12], which is used to simulate the ignition of interior solid materials in the current analysis, plays an important role in successfully simulating the spread of fire inside the train. This model has been used to successfully simulate fire spread in several real fire cases/experiments including, the Swissair MD-11 in-flight fire [12], the flame spread and the onset of flashover in a full-scale rail car fire test [13], the Station nightclub fire mock up test [14], the C133 aircraft post-crash fire experiment [15] and the Manchester B737 airport fire [16]. The method to calculate the generation of combustion products developed in [18, 19] is applied in this study to predict toxic gas species concentrations. In the fire analysis presented here the following hazards are predicted; temperatures, smoke concentrations (extinction coefficient), radiative flux, $\mathrm{CO}$ concentration, $\mathrm{CO}_{2}$ concentration and $\mathrm{O}_{2}$ concentration. Note that the generation of irritant fire gases is not included in these simulations.

The railEXODUS V2.2 software is part of the EXODUS suite of evacuation simulation software $[1,6,20]$. The railEXODUS software comprises five core interacting sub-models: the PASSENGER, MOVEMENT, BEHAVIOUR, TOXICITY and HAZARD. The PASSENGER sub-model describes an individual as a collection of defining attributes and variables such as name, gender, age, maximum unhindered fast walking speed, maximum unhindered walking speed, response time, agility, etc. The HAZARD sub-model controls the atmospheric and physical environment by importing the fire data. The TOXICITY submodel determines the physiological effects on an individual exposed to the toxic and thermal environment distributed by the HAZARD sub-model. This is determined using the Fractional Effective Dose (FED) and Fractional Irritant Concentration (FIC) concept [21]. Within railEXODUS two models are provided for the determination of the fractional effective dose of radiative heat, the so-called Pain Threshold model (in which the dose required to cause effect $\left(D_{r}\right)$ is 80 , which is the equivalent to an exposure of $2.5 \mathrm{~kW} / \mathrm{m}^{2}$ for $\left.24 \mathrm{sec}\right)$ and the Incapacitation model (in which $D_{r}=1000$, the equivalent to an exposure to $2.6 \mathrm{~kW} / \mathrm{m}^{2}$ for 5 min which can result in a $1 \%$ mortality) [14]. The Incapacitation model is used in these calculations. When a passenger moves through a smoke filled environment their travel speed is reduced according to the experimental data of Jin [22] which relates smoke extinction coefficient to walking speed. All these effects are communicated to the BEHAVIOUR submodel which, in turn, feeds through to the movement of the individual. The behaviours in railEXODUS include crawling, climbing over seats, wayfinding, etc. In the coupled fire and evacuation analysis presented here the following fire related parameters are considered:

- $\quad$ smoke extinction coefficient - related to walking speed using the Jin data [22].

- FIH - fractional incapacitating dose of heat, both radiative and convective (based on the Purser model described in [21]).

- FIN - fractional incapacitating dose of narcotic agents, which in this simulation include $\mathrm{CO}, \mathrm{CO}_{2}$ and $\mathrm{O}_{2}$ based on the Purser model described in [21]). 
An agent is considered incapacitated when the FED (either FIN or FIH) is equal to one. We also define severe injury as an agent that has an FED (either or both FIH or FIN) between 0.5 and 1.0.

Without the consideration of the interaction between fire and evacuation, the train fire safety assessment is only based on the predicted HRR, time to flashover in the fire car, the spread of fire from car to car and the levels of fire hazards, such as temperature, heat fluxes, smoke, toxic gases etc., at locations of interest. Using this approach an ASET or available safe egress time is produced which is then compared with the RSET or required safe egress time as determined from an evacuation simulation tool. The investigation of the fire growth and flame spread in Singapore Circle line OWG trains by Chiam [3] and fire spread in a reference rolling stock by Ting et al [4] followed this approach (see Fig. 3). However, this approach fails to take into consideration the complex nature of the coupled fire and evacuation dynamics and may provide an over-optimistic interpretation of the scenario outcomes.

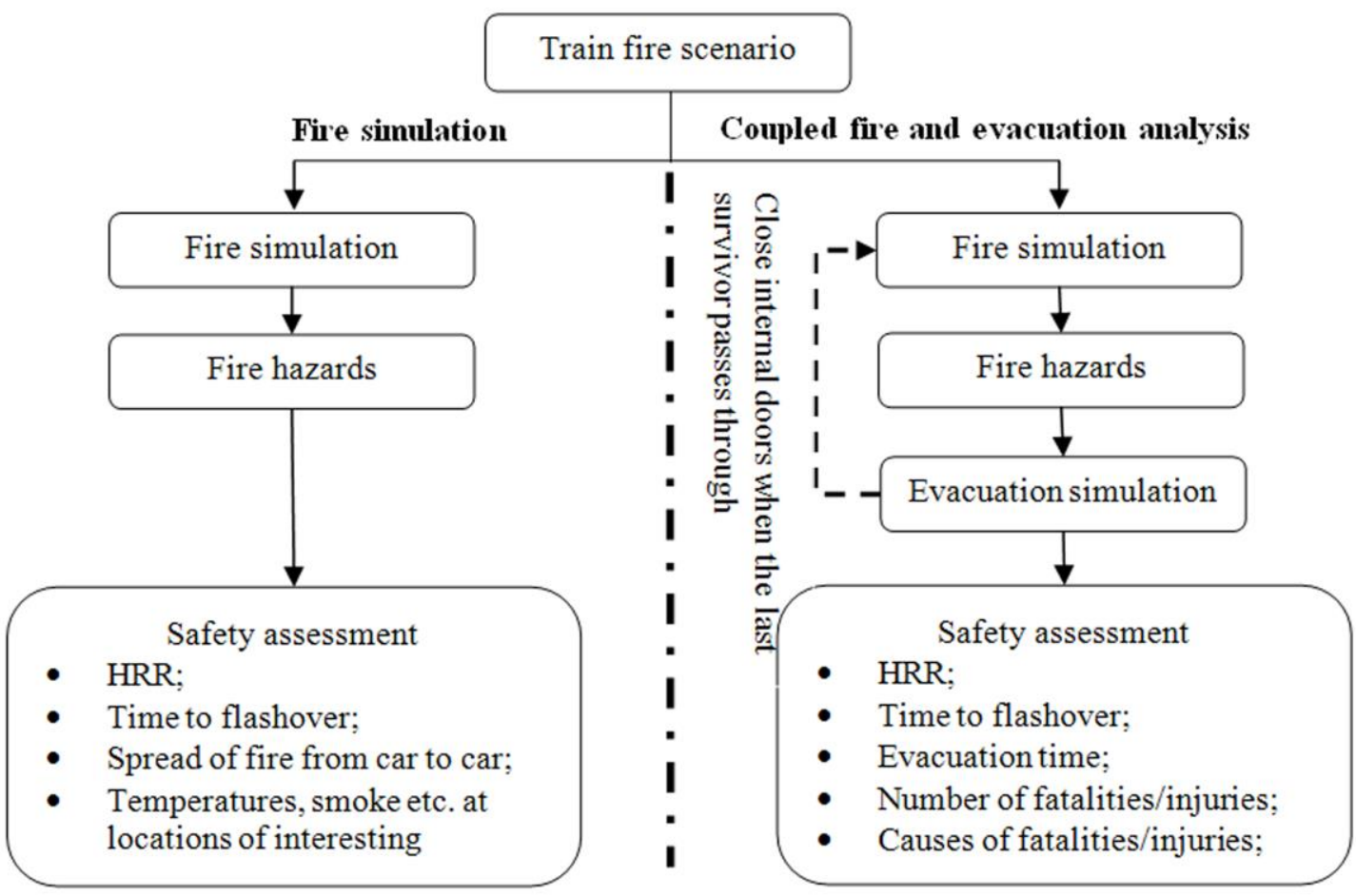

Fig. 3. Chart flows of fire and fire/evacuation assessments.

The fire and evacuation are coupled in two significant ways (Fig. 3). The passengers' actions may have a significant impact on the fire development and the spread of the fire effluents. Opening and closing internal doors will impact the ventilation within the train and hence the fire development and may also encourage or impede the spread of fire effluent to regions remote from the car of fire origin. Furthermore, the fire effluent will have an impact on the performance and behaviour of exposed passengers and so may adversely impact survivability as determined through the FED analysis. These underline the importance of performing coupled fire and evacuation analysis in fire safety assessment, rather than just an analysis with only fire or only evacuation simulation. Only when coupling the fire and the evacuation analysis a true understanding of the implications to survivability of train car design can be fully appreciated. In the coupled approach the simplistic ASET/RSET analysis is replaced by 
the direct evaluation of the number of casualties (predicted incapacitations and severe injuries) resulting from the evacuation subjected to the developing fire. The coupled fire and evacuation simulation technique using SMARTFIRE and EXODUS has been used in a number of applications including incident reconstruction, investigation, and engineering design $[14,16,17]$. In SMARTFIRE-EXODUS coupling, the computational domain used in the fire simulations is divided into a set of zones. The fire hazard data predicted by SMARTFIRE is averaged over these zones to produce two values: a hazard value at an arbitrary nominal head height, and a value at an arbitrary nominal knee height at each time step. The zone based hazard data produced by SMARTFIRE is then imported into the railEXODUS model into corresponding spatial zones. Within the railEXODUS model, when agents are considered to be standing, they are exposed to the hazards at head height; when the occupants elect to crawl, they are exposed to the hazards at knee height.

\section{SIMULATION SET UP}

\section{Fire simulations}

Each car in the four car train used in this study has interior dimensions of $2.6 \mathrm{~m}$ (wide) by 2.1 $\mathrm{m}$ (high) by $20 \mathrm{~m}$ (long). The side doors have dimensions of $1.2 \mathrm{~m}$ by $1.95 \mathrm{~m}$ while the end cab door has dimensions of $0.8 \mathrm{~m}$ by $1.9 \mathrm{~m}$. Train windows are usually made of laminated safety glass. When laminated window glass fractures, the broken fragments of glass will remain bond to the plastic interlayer under normal conditions [3]. Therefore, for simplicity, and as assumed in [3], the windows are assumed not to fall out in the present simulations. Thus the only venting of hot fire effluent into the tunnel is via any open doors. The section of tunnel modelled is $120 \mathrm{~m}$ long and $4.6 \mathrm{~m}$ (wide) by $4.0 \mathrm{~m}$ (high) (Fig. 4). The curved tunnel ceiling and side walls are represented by $0.1 \mathrm{~m}$ thick bricks. The $80 \mathrm{~m}$ long train is assumed to be $20 \mathrm{~m}$ into the tunnel.

The ignition sources are the two-luggage fire with and without accelerant shown in Fig. 2 . The volume of the ignition source is $0.5 \mathrm{~m}$ (wide) by $0.5 \mathrm{~m}$ (high) by $1.5 \mathrm{~m}$ (long) and is located on the floor beside three seats in Car 3 (Fig. 4). The material properties used in the simulations are presented in Table 2 and are the same used in [3] for the Singapore Circle Line rail stock unless indicated otherwise. The main interior combustible materials and the luggage fuel for the ignition source are assumed to have the molecular structure of Polyester, i.e., $\mathrm{C}_{5.77} \mathrm{H}_{6.25} \mathrm{O}_{1.63}$. Heat release rates measured under various levels of irradiance from cone calorimeter experiments are the inputs of the flame spread model. Cone calorimeter data under a heat flux of $25 \mathrm{~kW} / \mathrm{m}^{2}$ for carpet, $35 \mathrm{~kW} / \mathrm{m}^{2}$ for seats and $50 \mathrm{~kW} / \mathrm{m}^{2}$ for walls are appropriate in numerical simulations of train fires [3, 23]. The HRR curves of seats and carpet presented in Fig. 5 are those used for the Singapore Circle Line rail stock [3] and the HRR curve for walls is from [23]. The lateral flame spread rates are $0.0018 \mathrm{~m} / \mathrm{s}$ for the seats and the walls and $0.003 \mathrm{~m} / \mathrm{s}$ for the carpets, which are the upper limits for underground train materials according to British standard BS 6853 [2]. Due to the lack of a requirement for the upward flame spread rates within the standard, $0.0033 \mathrm{~m} / \mathrm{s}$ is used for all materials, which is the value for common aircraft panels [15]. Yields of combustion products are supposed to depend on the equivalence ratio and the yields against equivalence ratio have formulas derived by Tewarson in [24] for polystyrene, but the yields of species at well ventilated conditions are replaced with those for Polyester. 


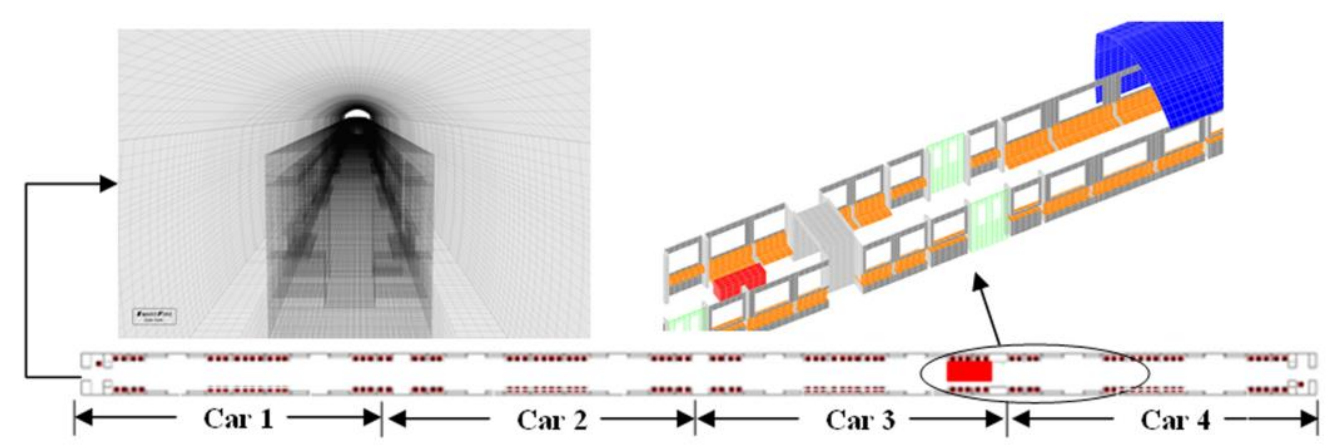

Fig. 4. CFD representation of the train inside the tunnel (left) and part of the train with the ignition source (right).

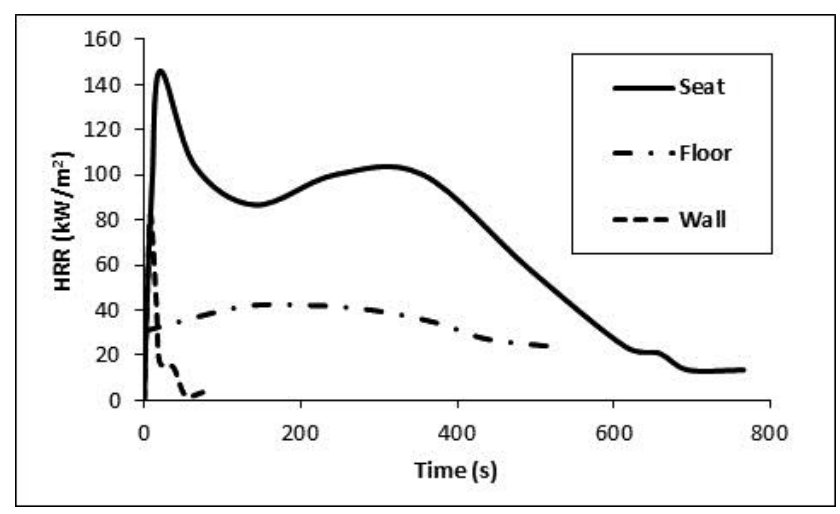

Fig. 5. HRRs of interior materials from cone calorimeter experiments.

Table 2. Material properties [3].

\begin{tabular}{|l|c|c|c|c|}
\hline & Density (kg/m3) & $\begin{array}{c}\text { Conductivity } \\
(\mathbf{W} / \mathbf{m K})\end{array}$ & $\begin{array}{c}\text { Specific Heat } \\
(\mathbf{J} / \mathbf{k g})\end{array}$ & $\begin{array}{c}\text { Ignition } \\
\text { temperature }\left({ }^{\mathbf{O}} \mathbf{C}\right)\end{array}$ \\
\hline FRP Polyester & 1795 & 0.295 & 1673.5 & 448 \\
\hline Styrene butadiene & 1478 & 0.19 & 1987.5 & 419 \\
\hline Wall panel & $548^{\mathrm{a}}$ & $0.11^{\mathrm{a}}$ & $2500^{\mathrm{a}}$ & 648 \\
\hline Glass & 1380 & 0.049 & 0.84 & -- \\
\hline
\end{tabular}

${ }^{\mathrm{a}}$ Data from [23].

Mesh sensitivity studies are undertaken within a single car as it would require a prohibitive amount of time to simulate a fire within the entire train with very fine meshes. Non-uniform meshes consisting of 90,729 and 205,020 cells for a single car are used in the mesh sensitivity study. The almost identical predicted temperatures at $1.7 \mathrm{~m}$ above the floor at the centre of the car for the two different mesh scenarios suggest that meshes consisting of 90,729 cells be adequate for the train car fire simulations. The entire computational domain of the four-car train and the $120 \mathrm{~m}$ long tunnel consists of 602,805 cells. Figure 4 is the CFD representation of the train inside the tunnel and part of the train with the ignition source.

The time step size used in the simulations is 2 seconds. A 600 seconds fire is simulated for scenarios with the side passenger doors open while 1200 seconds of fire is simulated for scenarios with the end cab doors open.

\section{Evacuation simulations}


It is assumed that there are a total of 715 passengers in the fully loaded four-car train. This population is distributed between the cars as follows; 172 agents in the car of fire origin, and 181 agents in each of the non-fire cars and randomly distributed within each car. Within the car of fire origin, agents are not placed near the location of fire initiation. Other passenger attributes assume the standard railEXODUS default values with a response time distribution of 0 to 30 seconds. In cases with the half loaded train, a total of 360 agents are used and are distributed as follows; 84 agents in the car of fire origin and 92 agents in each of the non-fire cars. In the OWG scenarios, agents are allowed to move from car to car. In the ID scenarios, the internal doors are closed when the side passenger doors are used for evacuation. In scenarios in which the end cab doors are used for evacuation, each internal door is assumed to be initially open and is closed after the last surviving agent passes through it. The times to close the internal doors are a result of the interaction between the fire and evacuation dynamics.

The door flow rate is an essential parameter determining the evacuation efficiency. The conventional train internal door only allows one agent to pass through at a time. The width at the bottom of the OWG connecting cars is $1.2 \mathrm{~m}$ (see Fig. 1). This is considered to be sufficiently wide to allow two people to pass through simultaneously. Passenger exit flow rates from the rail car to the track side can be extremely slow as passengers must negotiate a greater than $1 \mathrm{~m}$ drop from the car door sill to the ground. Non-emergency detraining incidents have produced exit flows of as low as 5 persons/minute with populations involving the elderly people and children $[1,25]$. Evacuation trials involving young students have achieved exit flows of approximately 20 persons/minute through side doors, while other trials using end doors have achieved average flows of 10 persons/minute [1]. In this study, a maximum flow of 10 persons/minute is assumed for the narrow cab end door and 20 persons/minute for the wide car side doors.

In scenarios involving car side doors, it is assumed that the tunnel is only sufficiently wide to allow doors on one side of the tunnel to open and that there is a $0.6 \mathrm{~m}$ wide walkway running along the tunnel side wall (See Fig. 6). The walkway is wide enough to allow agents to walk in single file. In these scenarios, passengers step down onto the walkway from train cars and walk in one direction towards the front of the train. In scenarios with the side doors closed, passengers step down onto the ground through the end doors located at either end of the train. As the fire hazards exit the rail car, they rise to the ceiling of the tunnel. Furthermore, as the agents exit the rail cars, they drop $1 \mathrm{~m}$ below the floor of the rail cars to the walkway/ground. As a result, with the exception of thermal radiation, the fire hazards within the tunnel are well above head height and so the agents experience a low level of fire hazards while in the tunnel. While the end of the tunnel is $20 \mathrm{~m}$ from either end of the train, agents are assumed to have reached a place of relative safety when they have travelled $4 \mathrm{~m}$ from the end of the train. Thus the end of the evacuation sequence for each agent is considered not when they have exited the train but when they have reached a place of relative safety - $4 \mathrm{~m}$ from the end of the train. It is noted that agents may still be incapacitated due to exposure to fire effluent while in the tunnel before they reach the place of relative safety. 


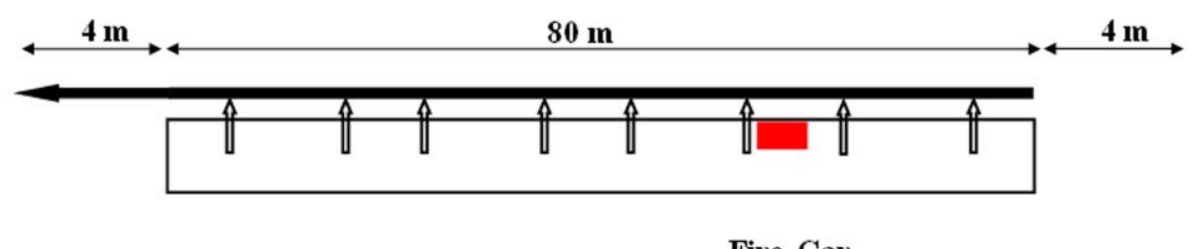

(a)

Fire Car

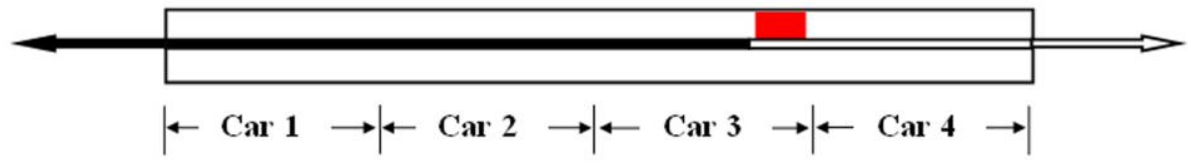

Fig. 6. Passenger evacuation flow with (a) side car doors open and (b) cab end doors open.

Passenger behaviour has been simplified in the evacuation simulations. Firstly, passenger response times are randomly generated between 0 and 30 seconds after the start of the fire, without considering the impact of visual access to the incident - which may increase or decrease response times. It is also assumed that there is no passenger intervention to suppress the fire. Furthermore, while passenger walking speeds assume the standard railEXODUS distribution (each passenger has a different walking speed) it is assumed that there are no mobility impaired passengers and it is further assumed that passengers are not hindered by luggage. It is also noted that the simplifying assumptions apply equally to both the OWG and ID scenarios.

For each scenario, 100 repetitions of the evacuation simulation are performed and the average result for the scenario is then determined. It should be noted that an agent that is incapacitated is considered a fatality as rescue is not considered in these simulations.

\section{SIMULATION RESULTS}

This analysis has involved 10 fire scenarios and 16 coupled fire and evacuation scenarios. Clearly this generates a significant amount of simulation data, too much to report in detail in this paper. Rather than present the full details of the fire and evacuation analysis this paper focuses on the key results that are important in differentiating the impact that the competing train configurations have on fire safety and survivability. Flashover is generally considered to mark the end of survivable conditions for occupants within a fire enclosure and has been used as a criterion to assess fire safety in some studies of train car fires [3,4]. Therefore, in the section 'Fire Simulation Results', the predicted HRRs - which is an indicator of the onset of flashover - for each scenario are presented. However, simply considering the onset of flashover is not sufficient to assess the life safety potential offered by the alternative designs. It is also essential to determine whether the exposed population can safely evacuate from the train during the developing fire. These results are presented in the sub-section 'Coupled Fire and Simulation Results'. The main results presented in this section are the number of predicted incapacitations generated in each scenario, from which the advantages/shortcomings of different car configurations are evaluated. Additional details useful in explaining the main findings such as hazard distributions and observed evacuation dynamics are presented in the section 'Further Analysis'.

\section{Fire Simulation Results}

The predicted heat release rates from the burning of train interior materials for all fire scenarios are depicted in Fig. 7. The minimum level of HRR for flashover in ISO 9705 room 
tests is $1000 \mathrm{~kW}$ [26]. However, the volume of a train car is much greater than the ISO 9705 test room. Thus it is reasonable to assume that a higher heat release rate would be required to indicate that flashover has occurred. Here we take flashover to be indicated by a rapid increase in the predicted heat release rate and the time to flashover to be arbitrarily defined as the time at which the heat release rate exceeds $2000 \mathrm{KW}$ within the train car. Therefore, for scenarios with the OWG configuration (Scenarios S1, S3, S5 and S7), flashover is unlikely to occur, based on these criteria. The maximum predicted peak HRR from the burning of train interior materials is approximately $250 \mathrm{~kW}$ occurring in Scenario S7 for the arson fire with only the end cab doors open for evacuation. Scenario $\mathrm{S} 1$ is similar to the fire simulation in the work by Ting et al [4] with the same ignition source and with the side doors open for ventilation. In this scenario, the predicted peak HRR is less than $120 \mathrm{~kW}$ during the 600 seconds simulation time. At this fire's peak, the car materials contribute an additional $24 \%$ to the peak heat released by the ignition source. This result is consistent with the finding from the work by Ting et al [4], in which they calculated an additional heat increase of $20 \%$. For the ID configuration, flashover is unlikely to occur too for scenarios with the car side doors open (Scenarios S2 and S6) with similar HRR curves as the scenarios for the OWG configuration. The two car separation configurations, OWG and ID, have minimal effect on the burning of train interior materials when the car side doors are open.

However, for the ID configuration, flashover is predicted to occur within the fire car for scenarios in which only the end cab doors can be opened into the tunnel. The predicted HRRs reach $2000 \mathrm{~kW}$ at 780 seconds in Scenario S4a, at 480 seconds in Scenario 4b, at 435 seconds in Scenario S8a and at 395 seconds in Scenario S8b respectively. The times to flashover are different for S4a and S4b and for S8a and S8b because the doors between cars are open for different durations due to the difference in the number of agents moving between cars. For example with the accidental fire, in Scenario S4a the cars are fully loaded and so the inter-car doors remain open for longer than in S4b in which the cars are only half loaded. In Scenario S4a (fully loaded) the doors between the car of fire origin and Car 4 and between the car of fire origin and Car 2 are closed at 300 seconds and 420 seconds respectively (see Table 3). In contrast, in Scenario S4b (half loaded) the two inter-car doors are closed at 20 seconds and at 110 seconds respectively. The earlier closure of the inter-car doors in S4b results in the earlier occurrence of flashover within the car of fire origin compared with Scenario S4a.

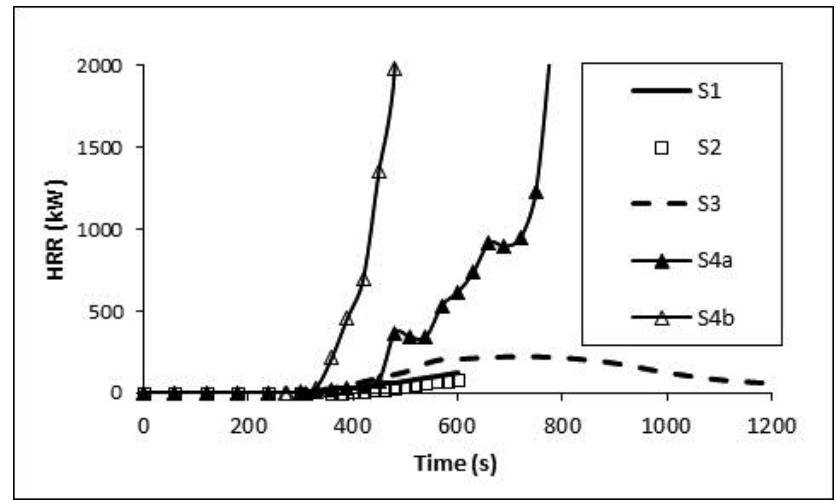

(a) 


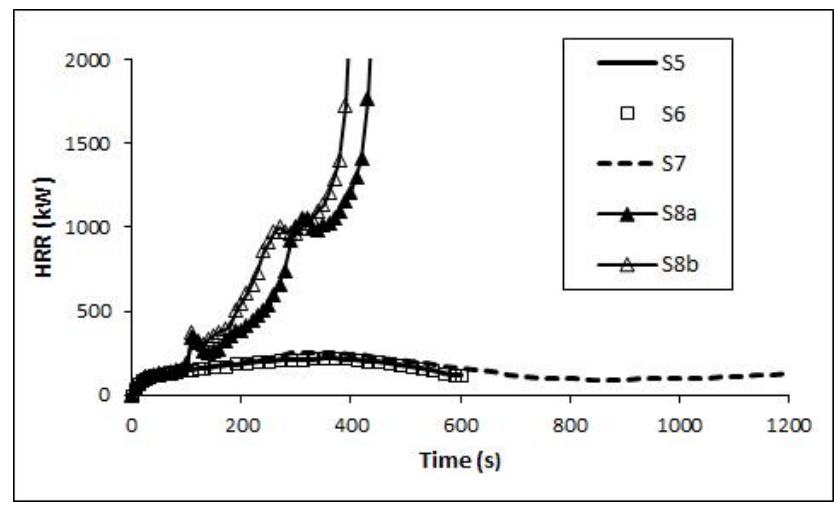

(b)

Fig. 7. Predicted HRRs from combustion of train interior materials for (a) the accidental fire scenarios and (b) the arson fire scenarios.

Table 3. Time to close the internal car doors in the ID configuration scenarios with the end cab door open.

\begin{tabular}{|c|c|c|c|}
\hline Scenario & Between Cars 1-2 (s) & Between Cars 2-3 (s) & Between Cars 3-4 (s) \\
\hline S4a & $>1200$ & 420 & 300 \\
\hline S4b & 720 & 110 & 20 \\
\hline S8a & 300 & 120 & 60 \\
\hline S8b & 300 & 110 & 20 \\
\hline
\end{tabular}

For scenarios with the train side doors open, both the OWG and the ID configurations result in only the seat bases near the fire source being involved in the fire. This means that the ignition source fire burns out without significant involvement of the car contents. However, for scenarios with the end cab door open, large differences in the burning areas between the two different train car separation configurations are predicted. As seen in Fig. 8, at the end of the simulation of the 1200 seconds fire in Scenario S3, only the seats near the fire source and the adjacent wall are involved in the fire (each black dot within the three-dimensional figures represents a computational cell which has been consumed by the fire). In contrast, most of the interior fittings within the car of fire origin are burnt out at 450 seconds in Scenario S4b.

From the predicted HRR and the burnt state of the train interior materials, we arrive at the same conclusion as in [4], namely that the use of flame retardant materials which are compliant with BS6853 Cat 1a prevents flashover and the uncontrolled spread of fire to adjacent cars for the OWG configuration. And the OWG configuration produces improved fire results in the car of fire origin compared to the conventional configuration.

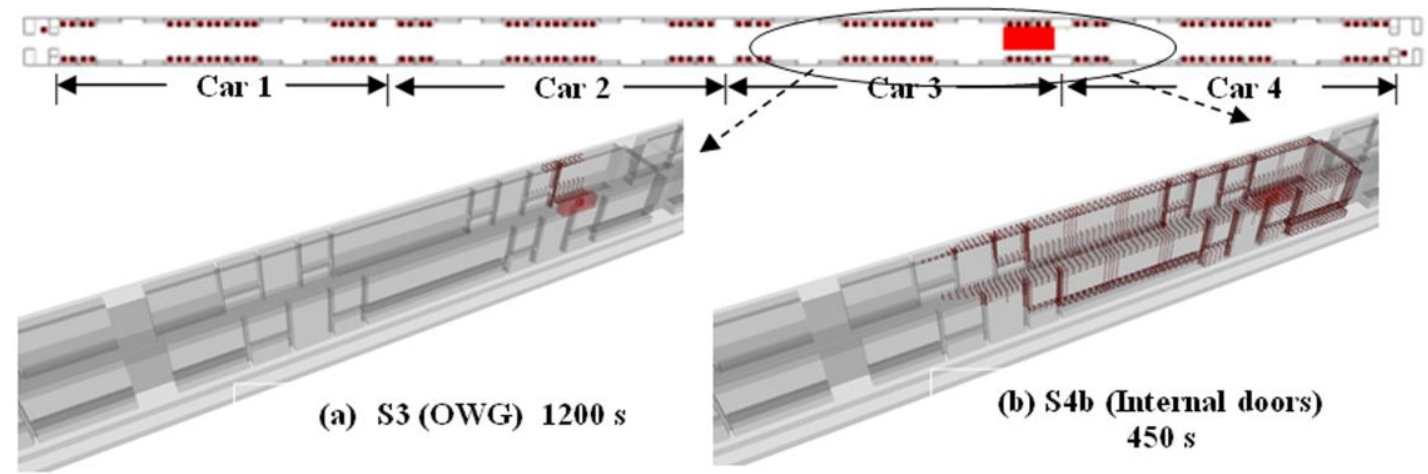

Fig. 8. Predicted burning locations at 1200s for Scenarios (a) S3 and (b) S4b. 


\section{Coupled Fire and Evacuation Simulation Results}

Before presenting the results of the coupled fire and evacuation analysis it is useful to determine required safe egress times (RSET) for the train as a whole and individual cars for a fully loaded train without fire hazards. When the train doors on one side are available for evacuation, it requires approximately 370 seconds, 435 seconds, 450 seconds and 470 seconds to empty Car 1, Car 2, Car 3 and Car 4 respectively. The differences in evacuation time for the different internal configurations are negligible as all the agents are using only the car side doors for evacuation. The RSET times increase for each car as the external evacuation flow is in one direction (see Fig. 6) and congestion develops along the side walkway (Fig. 14) making it difficult for agents to exit the cars. Thus the RSET for the train as a whole is 470 seconds. When only the train end cab doors are available for evacuation, the total evacuation time is approximately 3000 seconds, again irrespective of the nature of the internal layout. This is because the evacuation time is severely limited by the restricted flow through the two cab end doors. It requires 1310 seconds and 1341 seconds to empty Car 3 (Fire Car) for the OWG and ID car separation respectively.

The evacuation results under the impact of fire hazards from each corresponding fire scenario are presented in Table 4. All the predicted incapacitations are due to excessive heat exposure $(\mathrm{FIH}=1.0)$ while the severe injuries are due to a combination of heat and toxic gas exposure. Amongst the severe injuries, agents either had FIH greater than 0.5 or a combination of FIH and FIN greater than 0.5 .

The evacuation time presented in Table 4 is taken as the time for the last surviving agent to reach a place of relative safety. It is noted that in all cases, the evacuation times for cases using the side doors are significantly lower than those using the cab end doors. This is to be expected as the flow through a side door is twice that of an end door and there are eight usable side doors compared to only two usable end doors. However, the difference in evacuation time for side door versus end door is not consistent between OWG and ID configurations. This is due to the number of incapacitations occurring in the various scenarios. There are always more incapacitations when only the cab end doors are available compared to the case when the side doors are available irrespective of internal configuration, and with one exception (half load population, accidental fire, side doors available), there are always more incapacitations occurring for the OWG configuration compared to the ID configuration, irrespective of exit availability.

With the car side doors open for evacuation, the scenarios with OWG configuration (S1a, S1b, $\mathrm{S} 5 \mathrm{a}, \mathrm{S} 5 \mathrm{~b}$ ) produce similar evacuation times to the corresponding scenarios with the ID configuration (S2a, S2b, S6a, S6b). However, when only the end cab doors are available for evacuation, the scenarios with OWG configuration (S3a, S3b, S7a, S7b) produce evacuation times that are much shorter than that for the corresponding scenarios with the ID configuration (S4a, S4b, S8a, S8b). The reason for the shorter evacuation times in the OWG configuration is not the result of a more efficient movement of passengers from car to car, but is due to there being fewer survivors compared to the scenarios with the ID configuration. For example, in Scenario S3b the half loaded OWG configuration produces an evacuation time of 1419 seconds, which is $13 \%$ shorter than the corresponding 1624 seconds required by the equivalent ID configuration in Scenario S4b. However, in Scenario S3b there are 67.6 incapacitations compared with 0 in Scenario S4b.

Table 4. Average evacuation statistics for all scenarios. 


\begin{tabular}{|c|c|c|c|c|c|c|}
\hline & Scenario & $\begin{array}{c}\text { Population } \\
\text { load }\end{array}$ & $\begin{array}{c}\text { Evacuation } \\
\text { time (s) }\end{array}$ & $\begin{array}{c}\text { Severe injuries } \\
\text { (survivors with } \\
1>\text { FED }>0.5 \text { ) }\end{array}$ & $\begin{array}{c}\text { Total No. of } \\
\text { incapacitations } \\
(\text { FED }=1) / \%\end{array}$ & $\begin{array}{c}\text { No. of } \\
\text { incapacitations } \\
\text { within tunnel }\end{array}$ \\
\hline & Accidental Fire & & & & & \\
\hline \multirow{4}{*}{$\begin{array}{c}\text { Side } \\
\text { doors } \\
\text { open }\end{array}$} & S1a (OWG) & 715 & 743 & 59.0 & $73.7 / 10.3 \%$ & 3.6 \\
\hline & S2a (ID) & 715 & 666 & 6.8 & $49.1 / 7 \%$ & 1.6 \\
\hline & S1b (OWG) & 360 & 285 & $\mathbf{0}$ & $\mathbf{0}$ & $\mathbf{0}$ \\
\hline & S2b (ID) & 360 & 290 & 0 & 0 & 0 \\
\hline \multirow{5}{*}{$\begin{array}{c}\text { Only } \\
\text { end } \\
\text { cab } \\
\text { doors }\end{array}$} & S3a (OWG) & 715 & 1448 & 77.9 & $419.7 / 59 \%$ & 0.4 \\
\hline & S4a (ID) & 715 & 2356 & 67.0 & $185.6 / 26 \%$ & 0 \\
\hline & S3b (OWG) & 360 & 1419 & 71.6 & $67.6 / 19 \%$ & 0.4 \\
\hline & S4b (ID) & 360 & 1624 & 0 & 0 & 0 \\
\hline & Arson Fire & & & & & \\
\hline \multirow{4}{*}{$\begin{array}{l}\text { Side } \\
\text { doors } \\
\text { open }\end{array}$} & S5a (OWG) & 715 & 666 & 27.5 & $254.7 / 36 \%$ & 6.3 \\
\hline & S6a (ID) & 715 & 530 & 9.2 & $136.5 / 19 \%$ & 1.0 \\
\hline & S5b (OWG) & 360 & 432 & 12.3 & $32.8 / 9 \%$ & 3.8 \\
\hline & S6b (ID) & 360 & 310 & 6.0 & $29.2 / 8 \%$ & 1.3 \\
\hline \multirow{4}{*}{$\begin{array}{c}\text { Only } \\
\text { end } \\
\text { cab } \\
\text { doors }\end{array}$} & S7a (OWG) & 715 & 917 & 70.5 & $549.9 / 77 \%$ & 0.5 \\
\hline & S8a (ID) & 715 & 2364 & 140.0 & $171.0 / 24 \%$ & 0 \\
\hline & S7b (OWG) & 360 & 910 & 70.0 & $194.3 / 54 \%$ & 0.3 \\
\hline & S8b (ID) & 360 & 1549 & 12.7 & $22.0 / 6 \%$ & 0 \\
\hline
\end{tabular}

Among the eight pairs of the scenarios, only one pair, S1b and S2b (the accidental fire with the side doors open for evacuation and half passenger load) produce no incapacitations or severe injuries for both train car separation configurations. In all other scenario pairings the OWG configuration results in a greater number of incapacitations than the conventional ID configuration. The scenario producing the least additional incapacitations in the OWG configuration is S5b (the arson fire with the half loaded population and with the side doors open) which results in 32.8 incapacitations, 3.6 more than in the ID case (S6b). The scenario producing the greatest number of additional incapacitations is S7a (the arson fire with the fully loaded population and with the end cab doors open) which results in 549.9 incapacitations, 378.9 or at least $221 \%$ more incapacitations than in the ID case (S8a).

For the accidental fire, the scenario involving fully loaded cars with the cab end doors used for evacuation with OWG configuration (S3a) produces the highest number of incapacitations (419.7) and the greatest proportion of fatalities 59\%. Similarly, for the arson fire, the same configuration produces the highest number of incapacitations (549.9) and results in the greatest proportion of fatalities $77 \%$.

The OWG configuration also generally results in more passengers with severe injuries than the ID configuration except for the arson fire with the fully loaded population and with the end cab doors open for evacuation. In this situation, the OWG configuration (Scenario S7a) results in 70.5 severe injuries while the ID configuration (Scenario S8a) results in 140.0 injuries. However, the total number of casualties (severe injuries plus incapacitations) in Scenario S7a is 620.4, more than twice as much as in Scenario S8a (309.4).

While the fire in the car of fire origin within the OWG case may appear to be less severe than in the ID configuration, when the impact of the fire hazards on evacuation is considered, the OWG configuration results in a significantly greater number of predicted casualties and so is considered to be less safe than the ID configuration for the scenarios considered.

It is also noted that virtually all of the incapacitations occur within the rail cars. Very few incapacitations occur within the tunnel (see Table 4). Furthermore, those incapacitations that 
occur in the tunnel occur immediately the agent exits the rail car and so are not caused by conditions within the tunnel.

\section{Further Analysis}

While the fire simulations demonstrate that the OWG train car separation configuration successfully reduces the spread of fire over the train material surfaces (seats and walls) and delays (prevents) the onset of flashover, the evacuation simulations demonstrate that for the fire and exit scenarios considered, it results in considerably more casualties and so is significantly less safe than the conventional ID configuration. These counterintuitive findings are explained in this section through further analysis of the complex coupling between the fire and evacuation dynamics.

Firstly, the OWG configuration compromises the concept of a place of relative safety on board the train even in the situation with the side doors open for evacuation (S1, S2, S5 and S6). In fire Scenario S1 and S2, the two car separation configurations, OWG and ID, have minimal effect on the burning of train interior materials (See Fig. 7a). However, the spread of the fire effluent within the train and its impact on the evacuating passengers are quite different. As seen in Fig. 9, the head height temperature in the car of fire origin (Car 3) in Scenario S2 (ID) has a peak value of $209^{\mathrm{O}} \mathrm{C}$ at 440 seconds. This temperature is higher than the critical value of $185^{\circ} \mathrm{C}$, exposed to which the time to incapacitation is only one minute [21]. The car of fire origin in Scenario S1 (OWG) has a peak temperature of $182{ }^{\circ} \mathrm{C}$, which is only $13 \%$ lower than that in the ID case. However, the peak temperature in Car 4 in the OWG case (Scenario S1) is as high as $135^{\circ} \mathrm{C}$, which is much higher than the near ambient temperature in the ID case (Scenario S2). It is noted that it requires approximately 450-470 seconds to empty Car 3 and Car 4 even without the impact of fire hazards. The lengthy evacuation time is due to the relatively low exit flow rate to the ground via the side doors compounded by the congestion on the side walkway in the tunnel. As a result, it is not surprising that many of the incapacitations are originally located in this non-fire car in Scenario S1a (OWG) while the incapacitations in Scenario S2a (ID) are localised in the car of fire origin only (Fig. 10).

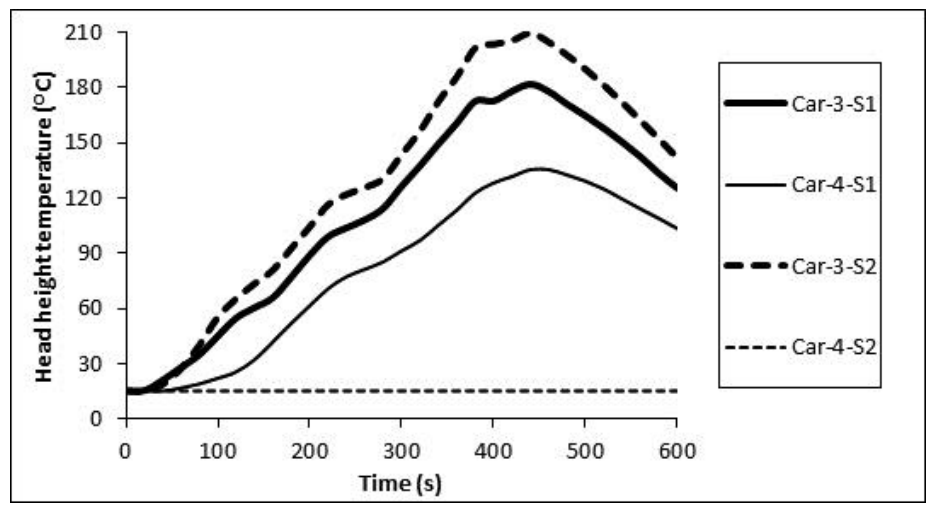

Fig. 9. Predicted head height temperatures in the centre of the fire car (Car 3) and Car 4 from Scenario $\mathrm{S} 1$ and $\mathrm{S} 2$. 


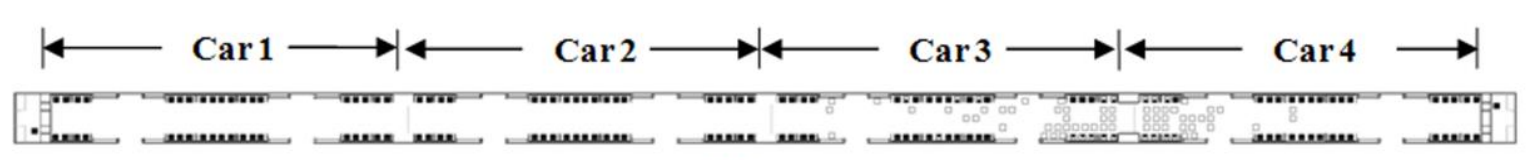

(a)

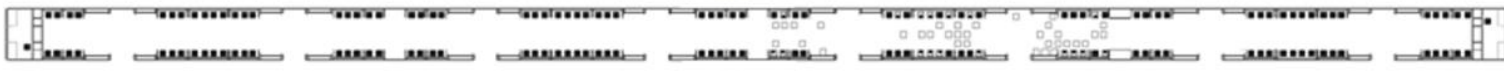

(b)

Fig. 10. Starting locations (open squares) of the predicted incapacitations in a single evacuation simulation of (a) S1a and (b) S2a.

Secondly, the agents cannot always take full advantage of the OWG configuration to enable the free movement of passengers between cars, in the event of a fire. In the OWG scenarios with open side doors for evacuation, the number of agents that move between cars is quite small (see Table 5). This is due to the high population density within the cars and the availability of exits to the outside in each car. As seen in Table 5, an average of 10.5 agents move from the car of fire origin to Car 4 and an average of 24.0 agents move to Car 2 in the high density population case with the accidental fire (Scenario S1a). Also with the high population density, the number of agents moving from the car of fire origin to its neighbouring cars in Scenario S5a in the arson fire is even less. In the lower population density cases, even fewer agents move between cars as the exit queues are sufficiently short for most agents to exit the train from the car where they are originally located.

Table 5. Average evacuation statistics for agents moving between cars for scenarios with OWG configuration.

\begin{tabular}{|c|c|c|c|}
\hline Scenario & From Car 2 to Car 1 & From Car 3 to Car 2 & From Car 3 to Car 4 \\
\hline S1a & 13.6 & 24.0 & 10.5 \\
\hline S1b & 4 & 11 & 5 \\
\hline S5a & 13.7 & 6.3 & 4.4 \\
\hline S5b & 4 & 11 & 5.7 \\
\hline
\end{tabular}

Thirdly, when only the end cab doors are available for evacuation, the OWG configuration places passengers in non-fire cars at a greater risk of injury in the event of fire. The discussion here is only based on the accidental fire scenario as the arson fire produces even worse fire hazards. In situations where it is not possible to open the car side doors for evacuation, flashover is prevented from occurring in the OWG configuration (Scenario S3) whereas in the ID configuration (Scenario S4a) flashover can occur within the car of fire origin after approximately 450 seconds. The initial fire development in Scenario S3 and Scenario S4a are similar (Fig. 11). However, once the doors to the fire car are closed in Scenario S4a, the upper layer temperature (Fig. 11a) and hot layer depth increase rapidly. As a result, the fire starts to spread to the interior materials of the fire car. It is not surprising that the predicted head height temperatures in the centre of the car of fire origin in Scenario S4a (ID) are significantly higher than those in Scenario S3 (OWG) after the internal door between the fire car and Car 4 is closed at 300 seconds (Fig. 11a). However, the predicted head height temperatures in the centre of each non-fire car in Scenario S4a are significantly lower than those in Scenario S3, especially after 500 seconds. The trends for the predicted CO concentrations at head height are similar to those for temperature (Fig. 11b). As the evacuation is limited by the occupant flow at the two cab doors, agents cannot benefit from the improved access between cars offered by the OWG configuration. This is demonstrated by considering the time to clear Car 3 in situations without fire. In the OWG configuration, the time to clear Car 3 is only 31 seconds or $2.3 \%$ faster than in the ID configuration, with approximately 1300 seconds being required to clear the car. Furthermore, the OWG 
configuration creates a free path for the fire effluent to move between cars making the nonfire cars untenable sooner than in the case of the conventional car configuration. As a result, almost all the agents in the car of fire origin and most of the agents in Car 2 and Car 4 become incapacitated in Scenario S3a (see Fig. 12). In contrast to the hazardous environment in Scenario S3, the temperatures and CO concentrations in the non-fire cars in Scenario S4a are considerably lower. As a result, only the agents in the car of fire origin and a small number of agents in Car 4 are incapacitated. In the car of fire origin, seven agents survive and move into neighboring cars before the internal doors to the fire car are closed in Scenario S4a.

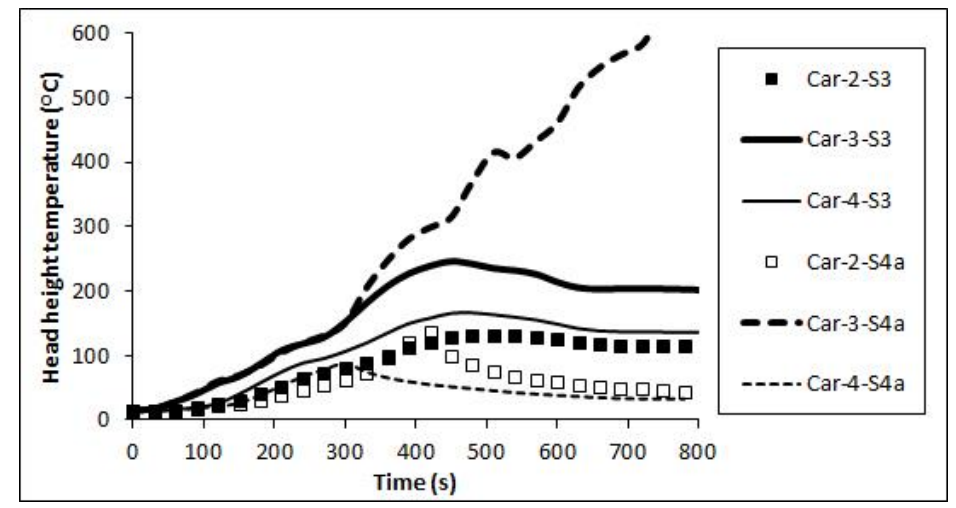

(a)

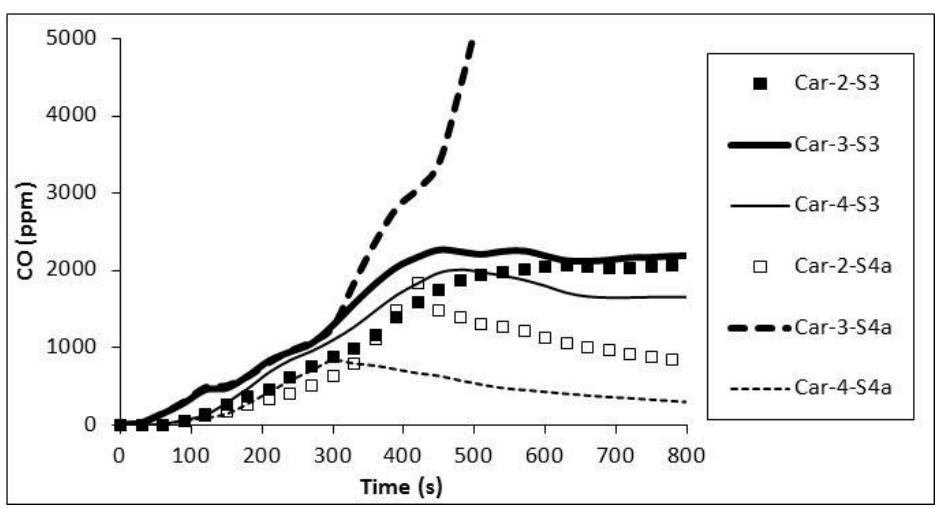

(b)

Fig. 11. Predicted head height (a) temperatures and (b) CO concentrations in the centre of each car from Scenario S3 and S4a.

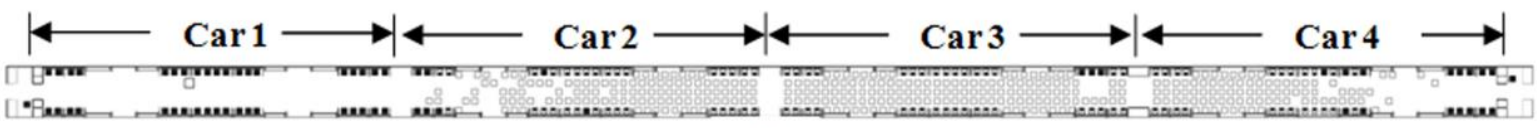

(a)

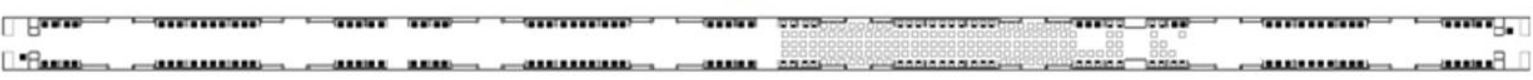

(b)

Fig. 12. Starting locations (open squares) of the predicted incapacitation in a single evacuation simulation of (a) S3a and (b) S4a.

Finally, while the time to flashover is generally considered to mark the end of the survivability period for those passengers still remaining in the car of fire origin, flashover is not the determining factor for survivability in the scenarios investigated in this study. Firstly, 
for all the scenarios involving the ID configuration, flashover occurs after the last survivor originally located in the car of fire origin exits the car and shuts the door behind them. For example, in Scenario 8a (ID), time to flashover is 435 seconds based on a HRR criterion of 2 MW as defined in this study. A more conservative time to flashover is 345 seconds, based on a flashover criterion of $1 \mathrm{MW}$ as determined in the ISO 9705 room fire test [26], or 330 seconds using another conservative flashover criterion based on the upper layer temperature exceeding $600{ }^{\circ} \mathrm{C}$. However, in this scenario, the last survivor in the car of fire origin (Car 3 ) has exited the car and closed the door at 120 seconds, well before flashover occurs. Secondly, at the time the doors to the car of fire origin are closed, both OWG and ID configurations result in similar numbers of incapacitations. For example, at the time both doors to the car of fire origin are closed, $97 \%$ of the 172 passengers originally located in the car of fire origin have been incapacitated in Scenario 8a (ID). In contrast, in Scenario 7a (OWG) at the same time, $94 \%$ of the 172 passengers have been incapacitated in the car of fire origin. Therefore, the survivability within the car of fire origin is not determined by the time to flashover for both OWG and ID configurations. Thus it is not appropriate to use flashover as the sole indicator for fire safety assessment for underground trains - as suggested in earlier studies $[3,4]$.

\section{CAR SEPARATION EVALUATION}

A critical fire safety criterion for a rail car configuration is that the passengers can safely evacuate from the train in the event of a fire. The evacuation efficiencies in terms of the number of incapacitations for an underground train within a tunnel with the OWG and ID configurations have been compared in the previous section for an accidental luggage fire scenario and an arson fire scenario involving accelerants for ignition. The numbers of predicted incapacitations resulting from each scenario are compared in Fig. 13. It is clear that the conventional ID configuration results in a significantly safer evacuation performance than the OWG configuration in virtually all cases investigated in this study.

For the accidental fire, in the half loaded population scenario, all the agents in the ID configuration can safely evacuate if side doors or end cab doors are used. In this case agents in the OWG configuration can safely evacuate only if the side doors are available. If only the cab end doors are available for evacuation, on average 68 incapacitations may be caused. In scenarios in which the train is fully loaded, both configurations result in predicted incapacitations. However, the OWG configuration results in a significantly greater number of incapacitations, generating 50\% more in the case of a side door evacuation and $126 \%$ more in the case of a cab end door evacuation. Clearly, the scenario in which only the cab end doors are available for evacuation (narrow tunnel) is the most challenging for both configurations. For the arson fire, the OWG configuration again produces significantly greater incapacitations than the conventional ID configuration for all scenarios. 


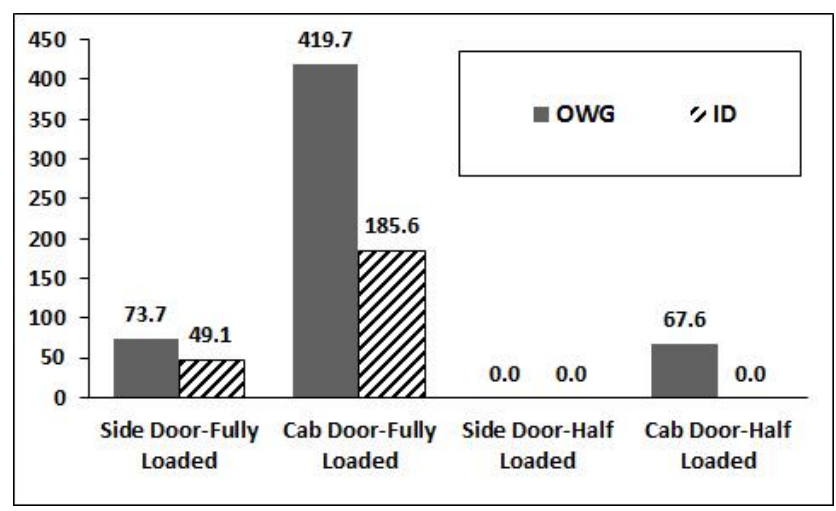

(a)

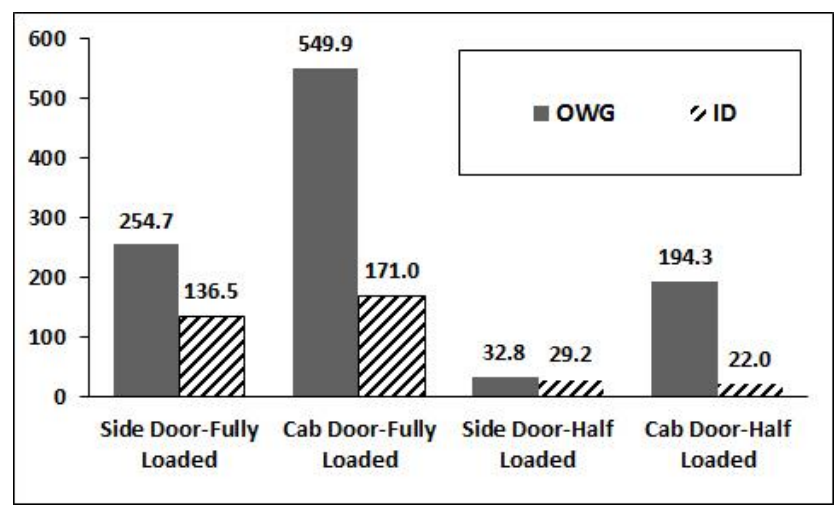

(b)

Fig. 13. Number of predicted incapacitations resulting from an (a) the accidental fire and (b) the arson fire for the OWG and ID configurations with fully loaded and half loaded populations.

It is noted that for the fully loaded ID configuration with only the cab end doors available for evacuation, the number of predicted incapacitations decreases as the HRR of the fire is increased from that of the accidental fire (S4a) to the arson fire (S8a). This result is counterintuitive as it is expected that as the HRR of the fire increases, there will be a greater number of incapacitations - as indeed there are in all the other scenarios. This result is due to the earlier closure of the doors either side of the car of fire origin in S8a (arson fire) compared to S4a (accidental fire) as shown in Table 3. Within the car of fire origin almost all of the agents are incapacitated within the car for both fire scenarios. However, with the less severe fire (S4a), the number of incapacitations within the car of fire origin is slightly lower on average and the incapacitations occur later compared with scenario S8a. Thus for the less severe fire, there are slightly more agents that survive on average and they survive for longer and so prolong the time at which the connecting doors remain open. As a result (of the greater survivor rate and survivor duration) a greater volume of fire effluent is able to spread to the neighbouring cars resulting in a greater incapacitation rate compared to the case with the larger fire. Thus the greater survival rate within the car of fire origin results in a greater incapacitation rate elsewhere in the train.

The key factors which contribute to the predicted number of incapacitations are the exiting flow of agents and the spread of fire effluent throughout the train. The exit flow is very low for both configurations due to the nature of the exit, involving a greater than $1.0 \mathrm{~m}$ drop from the rail car to the ground. If this could be improved with a better exiting mechanism, the number of incapacitations in both cases would be significantly reduced. The spread of fire 
effluent from the fire car to the neighbouring cars is directly affected by the nature of the car separation. In the case of the OWG cars the fire effluent is free to move between cars which will directly impact the ability of passenger to evacuate, a point not fully considered in the earlier fire analyses $[3,4]$ which did not include a coupled fire-evacuation analysis. While the OWG configuration allows easier movement of passengers between cars, in the fully loaded scenario, passengers cannot take the full advantage of this feature in the event of a fire and are significantly disadvantaged as they are exposed to much greater fire hazards in the OWG cars than in the ID cars.

For the situation of a train in a narrow tunnel, it is assumed in the above analysis that only the cab end doors are open and used for evacuation (worst door availability). While the side doors cannot be opened for evacuation, they may be opened for ventilation by passengers stuck in the cars. This case is evaluated for a fully loaded OWG configuration where the cab end doors are used for evacuation but the car side doors are opened for ventilation - Scenario S9. For simplicity, it is assumed that the doors on one side can be fully opened making the fire development in S9 in an OWG train similar to that in either S1 or S5 in which side doors are open for both ventilation and evacuation, depending on the type of the ignition source. This then creates a more survivable fire environment than those in either S3a or S7a with only the end cab doors open. Thus, the evacuation outcomes of S9 for an OWG configuration are expected to be worse than either S1a or S5a but better than those in either S3a or S7a. Evacuation simulations for S9 for the OWG configuration with the accidental fire produce an average of 270.3 incapacitations, less than that in S3a as expected, but still significantly higher than the number in the worst accident fire case for the ID configuration (185.6, Scenario S4a)). For the arson fire, the number of incapacitations in S9 is expected to be greater than that in S5a (254.7) (the least deadly arson fire case for OWG configuration), which is already much higher than the number in the worst arson fire case for the ID configuration (171 in S8a). Therefore, for a train with fully loaded population in a narrow tunnel, the OWG is expected to produce more incapacitations than those with the ID configuration in this particular evacuation situation.

A possible mitigation to improve the performance of the OWG configuration is the installation of a fire suppression system within the train. A potentially less complex solution would involve the installation of either fire doors which could be automatically deployed in the event of a fire or the installation of a passenger operated fire curtain. The later would rely on passengers correctly deploying the curtain. It is noted that the conventional configuration is also reliant on the last passenger to pass into a neighbouring car to close the door behind them.

\section{STUDY LIMITATIONS}

As in any numerical simulation of a complex process, there are many possible scenarios that can be examined. It is not practical to investigate all the possible scenarios that may be of interest and so the conclusions derived from this study are limited to the scenarios investigated. Furthermore, it is important to take into considered the nature of the assumptions required to simplify the analysis when reviewing the findings and conclusions. Here we list some of the known limitations of the work presented in this paper.

- A scenario in which both the left and right side doors are available for evacuation was not considered in this study. This scenario is expected to be the most survivable for both the OWG and ID configurations and so the least challenging and of least interest. 
Survival rates are expected to be better than those for the case with the side doors available on only one side.

- All the scenarios examined considered evacuation within a tunnel. Scenarios involving evacuation within a station were not considered as these are considered to be less challenging than those for Scenario 1, 2, 5 and 6 in which the side doors on one side of the train are available. When the train is at a station platform, the exit flow through each of the train side doors will be greater than when the train is in the tunnel as the passengers can simply walk out of the train onto the platform and do not have to descend to the ground. Furthermore, with the train in the station, the fire dynamics within the train cars may be different to that in the tunnel due to the different ventilation conditions and the evacuation of the passengers from the platform would also need to be considered. This would introduce another set of factors considered beyond the scope of this study.

- Only two types of ignition sources are considered in the fire simulations, a slowly developing luggage fire and an accelerant driven luggage fire with a peak HRR around $500 \mathrm{~kW}$. As an ignition source of between 25 and $200 \mathrm{~kW}$ is required to promote significant fire spread within trains [8], the use of smaller ignition sources may not result in fires as severe as those examined in this paper, and so the differences in survivability resulting from the OWG and ID configurations may not be as significant as suggested in this study. Conversely, for larger ignition sources, such as may result from a terrorist incident on an underground train, the suggested differences in survivability may be more pronounced.

- The results for the scenarios with the conventional internal door configuration (ID) are reliant on the assumption that the internal doors, in particular the doors of the car of fire origin, are intact and are closed after the last passenger exits into the neighbouring car. The complete closure of the doors to the fire cars is critical to the conclusions of this study. If the doors to the fire car are not completely closed or there is leakage, the fire effluent would spread to the adjacent cars and possibly produce more incapacitations than those predicted in this study for the ID configuration. Furthermore, if the doors are fully closed, but are closed at a time later than that used in the simulations, this will also impact the number of incapacitations.

- Ventilation of the rail cars was restricted only to certain car doors being open. While this situation was the same for both the OWG and ID configurations examined, it was most severely restricted in the scenarios with only the end doors open for evacuation i.e. S3, S4, S7 and S8 - which are the scenarios that resulted in the greatest number of incapacitations. It is possible that windows within the car of fire origin may break due to the fire, car doors could be opened even if they could not be used for evacuation and windows may be broken by the occupants, all of which would increase the ventilation within the cars. The improved ventilation is likely to have two effects. First it will reduce the volume of fire effluent within the train, allowing more of the fire effluent to be vented into the tunnel and out of the train making conditions more survivable within the train. This is likely to have the greatest positive impact on the survivability within the OWG train with the end doors used for evacuation. The additional scenario S9 partially addressed this case where all the doors on one side of the train were open, hence allowing for greater ventilation, even though they could not be used for evacuation. For the accidental fire this resulted in a $36 \%$ reduction in 
the number of incapacitations compared to S3a, but still resulted in 270 incapacitations or $38 \%$ of the occupants. While not examined in this paper, it is expected that if both sets of doors were open, the conditions and hence survivability would be improved still further.

The second impact of improved ventilation is that the fire within the car of fire origin is expected not to grow as fast or to reach the same peak HRR output. For example, in Figure 7a compare the heat release rate of the fires in the case of the ID configuration subjected to the accidental fire with the side doors open (S2) producing high ventilation - and with only the car end doors open (S4) - producing poor ventilation. As can be seen, the case with higher ventilation (S2) results in the smaller fire. For the case with the ID configuration it is not possible to determine whether this will result in fewer or greater incapacitations without performing coupled fire and evacuation simulations as the doors from the car of fire origin will be open for longer (as there are more survivors in the car of fire origin) which means more of the fire effluent will spread to the neighbouring cars. Conversely, for the OWG configuration, improved ventilation will reduce the size of the fire and hence reduce the amount of fire effluent available to spread to other cars and so is likely to reduce the number of incapacitations. However, it is not possible to determine the magnitude of the expected benefit without undertaking additional coupled fire and evacuation simulations.

- The impact of forced ventilation within the tunnel is not considered within this study. This is not expected to have a major impact on the findings of the study as it is the same for both train configurations, and as shown in Table 4 the vast majority of incapacitations occur within the train.

- The place of safety is only considered to be $4 \mathrm{~m}$ away from either end of the train. In reality, passengers may be expected to walk greater distances to reach safety, either a station or the tunnel exit. However, the main purpose of this study was to consider the impact of train configuration on survivability and so the study was primarily concerned with the analysis up to the point the passengers had exited the train. Furthermore, results suggest that conditions within the tunnel in the immediate vicinity of the train are survivable. However, it is interesting to note that considerable congestion develops along the narrow walkway as passengers exiting the train delay passengers already on the walkway (see Figure 14). In some situations this could be a significant factor resulting in delaying the passengers reaching a place of relative safety.

- The combustion model for the gaseous fuel assumes that the fire only selfextinguishes when the available $\mathrm{O}_{2}$ or fuel runs out. Thus for the ID scenarios, the HRR in the fire car after the internal doors are closed may be over-predicted as the fire continues to burn even though the $\mathrm{O}_{2}$ level may be insufficient to sustain flaming combustion. However, this modelling limitation does not affect the derived number of incapacitations in this study or the main conclusions. This is because, no survivors are in the fire car when its internal doors are closed; and because the impact of the fire hazards from the fire car (only heat transfer through the car walls/doors via conduction) on passengers in the tunnel and other cars are negligible. 
- Passenger behaviour in the evacuation simulations has been simplified so that the passenger population does not contain passengers with mobility impairments, luggage does not hinder the movement of passengers, the passenger response time is not impacted by visual access to the incident and there is no passenger intervention to suppress the fire. However, it is noted that the imposed passenger behaviour is the same for both the OWG and ID evacuation scenarios.

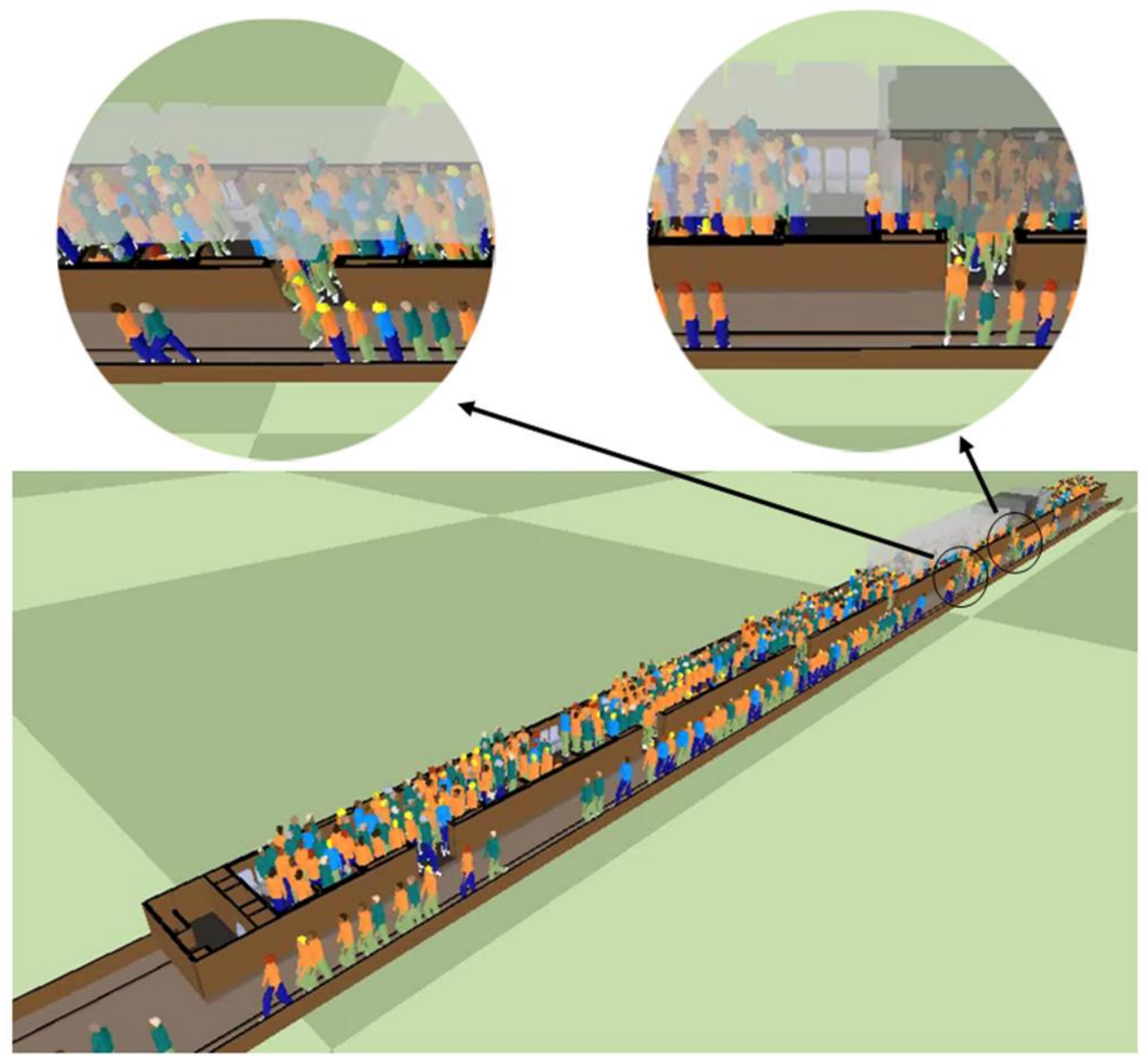

Fig. 14. Passengers on the narrow walkway are delayed by passengers exiting the rail cars.

\section{CONCLUSIONS}

In this paper we compared the fire safety performance offered by conventional underground train configurations, in which cars are separated by internal doors (ID), and the new open wide gangway $(\mathrm{OWG})$ configuration concept, in which the train interior is open from the rear car to the front one. Two underground train fire/evacuation situations were considered; one in which the car side doors are available for evacuation (the train in a wide tunnel) and the other in which only the end cab doors are available (the train in a narrow tunnel). Two population configurations were also considered, fully loaded and half loaded. In addition, two ignition sources are applied, representing an accidental fire and an arson fire. The analysis presented in this paper differs from previous published work on this topic as it includes both detailed fire and evacuation modelling and the fire modelling was coupled with the evacuation modelling. This type of analysis is essential in order to fully investigate the complex coupling between the fire and evacuation dynamics. 
When considering the conclusions of this work it is important to keep in mind the nature of the assumptions required to simplify the analysis. These included:

- Only two fire sources were considered involving a medium sized luggage fire with and without an accelerant;

- In the internal door configuration, the doors between cars are closed after the last surviving passenger has exited the car;

- The analysis did not include the impact of enhanced ventilation resulting from breakage of windows or opening of car doors that cannot be used for evacuation.

The main findings in this study are summarised as follows:

- The OWG configuration may produce improved fire conditions in the car of fire origin compared to the conventional configuration

- Flashover is unlikely to occur in all scenarios for trains with the OWG configuration with the use of flame retardant materials for interiors which are compliant with BS6853 Cat 1a;

- Flashover is predicted to occur within the car of fire origin for trains with the conventional ID configuration in situations where the car side doors are not opened for evacuation and only the end car doors can be opened into the tunnel, and the internal doors between cars are shut after the last survivor passes through the doorway.

- However, by taking into account the complex coupling between the fire and evacuation dynamics, for the scenarios examined, the OWG configuration is likely to result in significantly more casualties than the ID configuration. The difference in survivability is due primarily to the OWG train not being compartmented allowing fire effluent to rapidly spread from the car of fire origin throughout the entire train creating a hazardous environment for those still left on board during an evacuation. The impact of the spread of fire effluent throughout the train is accentuated in situations where the rapid evacuation of the passengers is delayed, such as when only the car end doors are available for evacuation (e.g. when the train is in a narrow tunnel) and when the train is fully loaded.

The findings of this study are particularly relevant to underground train systems in cities such as London that have a number of narrow tunnels on their underground network and have trains that are almost always fully loaded during rush hours. The most challenging situations involve fully loaded OWG trains subjected to fire in narrow tunnels where evacuation is only possible through the car end doors. While the differences in survivability between the OWG and ID train configurations is of concern for accidental fires, it is more significant in arson or terrorist inspired situations where the fire can be more severe.

A possible structural mitigation which may improve the performance of OWG cars is the introduction of passenger operated fire curtains between cars. However, this approach has the disadvantage of relying on the correct operation by passengers, as does the closing of the inter-car door in conventional rail cars. Finally, the impact of improved ventilation within the trains on passenger survivability is currently being investigated by the authors and will be the subject of a later publication.

Finally, an important general conclusion resulting from this work is that it is not appropriate to simply use the occurrence of flashover as the sole indicator for fire safety assessment in underground trains. The determination of the ability of the passengers to safely evacuate to a place of relative safety before conditions within the evacuation route deteriorate is essential, 
and so it is important to consider coupled fire and evacuation analysis. This finding is also applicable to fire safety assessment for other enclosures such as buildings.

\section{ACKNOWLEDGEMENTS}

The authors would like to thank the expert referees of this paper for their insightful comments which have improved the clarity of the paper.

\section{REFERENCES}

[1] Galea, E.R., Blackshields, D., Finney, K.M., and Cooney, D.P., "Passenger Train Emergency Systems: Development of Prototype railEXODUS Software for U.S. Passenger Rail Car Egress", U.S. Department of Transportation, Federal Railroad Administration, DOT/FRA/ORD-14/35, November 2014. http://ntl.bts.gov/lib/54000/54300/54305/railEXODUS_20141118_final.pdf

[2] British Standard. "Code of practice for fire precautions in the design and construction of passengers carrying trains”, BS 6853:1999, ISBN 058028240 X, 42 p.

[3] Chiam B.H., "Numerical simulation of a metro train fire", Fire Engineering Research Report 05/01, Department of Civil engineering, University of Canterbury, New Zealand, 2005, $340 \mathrm{p}$.

[4] Ting Y.S., Eckford D.C., Dinsdale-Yong O.R., Liang H., "Bowman I.N., Crossrail fire safety designs", $6^{\text {th }}$ International Conference 'Tunnel Safety and Ventilation', Graz, Austria, 2012, pp 108-115.

[5] Ewer, J., Grandison, A., Jia, F, Galea, E., Knight, B. and Patel, M., "User Guide and Technical Manual, SMARTFIRE V4.1", Fire Safety Engineering Group, the University of Greenwich, 2007.

[6] Galea, E.R., Blackshields, D., Lawrence, P.J., Finney, K., and Cooney, D., "The Development and Validation of a Rail Car Evacuation Model.", Proceedings of the 13th International Fire Science \& Engineering Conference, Interflam 2013 24-26th June 2013, Royal Holloway College, London, UK, Volume 2, pp. 1023-1034. ISBN 9780 9556548-9-3, 2013.

[7] Pritchard, R. "TfL's first Class 378 ready to roll!". Today's Railways UK (Sheffield). p. 32., November 2008.

[8] Peacock R.D., Averill J.D., Madrzykowski D., Stroup D.W., Reneke P.A. and Bukowski R.W., "Fire safety of passenger trains; Phase III: evaluation of fire hazard analysis using fullScale passenger rail car tests", NISTIR 6563, National Institute of Standards and Technology, USA, 2004, $149 \mathrm{p}$.

[9] Hong W. H., The progress and controlling situation of Daegu subway fire disaster, the $6^{\text {th }}$ symposium of AOFST, 2004.

[10] Anthony D. Putorti, J.r., Flammable and combustible liquid spill/burn patterns, NIJ Report 604-00, 2001, National Institute of Standards and Technology, Gaithersburg, MD 20899-8641.

[11] Rolling stock information sheet, London Underground, 2007.

[12] Jia F., Patel M.K., Galea E.R., Grandison A. and Ewer J., (2006) CFD Fire Simulation of the Swissair Flight 111 In-flight Fire - Part II: Fire Spread within the Simulated Area, The Aeronautical Journal of the Royal Aeronautical Society, 110:303-314.

[13] Hu X., Wang, Z., Jia, F. and Galea, E.R., (2012) Numerical investigation of fires in small rail car compartments, Journal of Fire Protection Engineering, 22:245-270. http://dx.doi.org/10.1177/1042391512459640

[14] Galea E. R., Wang Z., Veeraswamy A., Jia F., Lawrence P. J. and Ewer J., "Coupled fire/evacuation analysis of station nightclub fire", Fire Safety Science -- Proceedings of the 
Ninth International Symposium, International Association for Fire Safety Science, 2008, Karlsruhe, Germany, pp 465-476. http://dx.doi.org/10.3801/IAFSS.FSS.9-465

[15] Wang, Z., Jia, F., Galea, E.R., (2013) Computational fluid dynamics simulation of a post-crash aircraft fire test, Journal of Aircraft, 50: 164-175. http://dx.doi.org/10.2514/1.C031845

[16] Wang Z., Jia F. and Galea E.R., (2012) Fire and evacuation simulation of the fatal 1985 Manchester Airport B737 fire, Proceedings of the 5th international symposium, Human Behaviours in Fire 2012, Interscience Communications Ltd., pp. 159-170.

[17] Galea, E.R., Filippidis, L., Wang, Z., and Ewer, J., (2013) Fire and evacuation analysis in BWB aircraft configurations: computer simulations and large-scale evacuation experiment, The Aeronautical Journal of the Royal Aeronautical Society, 2010, 114, (1154), pp 271-277. [18] Wang Z., Jia F., and Galea E.R., (2007) Predicting toxic gas concentrations resulting from enclosure fires using local equivalence ratio concept linked to fire field models, Fire and Materials, 31:27-51. doi:10.1002/fam.924

[19] Wang, Z., Jia, F., Galea, Patel M.K., (2011) Predicting toxic gas concentrations at location from the fire source, Fire and Materials, 35:505-526. http://dx.doi.org/10.1002/fam.1069

[20] Gwynne, S., Galea, E., R.,Lawrence, L. and Filippidis, L., (2001) Modelling Occupant interaction with fire conditions using the buildingEXODUS evacuation model, Fire Safety Journal, 36:327-357. doi:10.1016/S0379-7112(00)00060-6

[21] Purser, D. A., "Toxicity assessment of combustion products", The SFPE, Handbook of Fire Protection Engineering ( $3^{\text {rd }}$ Edition), Ed: Dilenno, P.J., Drysdale, D., Beyler, C.L., Walton, W.D., Custer, R.L.P., Hall, J.R., and Watts, J.M.W., National Fire Protection Association, Quincy, MA 02269, 2009, p. 2/96.

[22] Jin, T and Yamada, T. (1985) Irritating Effects From Fire Smoke On Visibility, Fire Science and Technology, 5:79-90.

[23] Hjohlman M., Försth M., Axelsson J., Design fire for a train compartment, SP Report 2009:08; Fire Technology, SP Technical Research Institute of Sweden, 77 p.

[24] Tewarson, A., "generation of heat and chemical compounds in fires", The SFPE handbook of fire protection engineering, $2^{\text {nd }}$ edition, published by the National Fire Protection Association, Quincy, MA 02269, 1995, p. 3/53.

[25] Galea E.R. and Gwynne S. "Estimating the flow rate capacity of an overturned rail carriage end exit in the presence of smoke." Fire and Materials, 24, pp 291-302, 2000. DOI: $10.1002 / 1099-1018(200011 / 12) 24$.

[26] Babrauskas V., Peacock R.D., Reneke P.A., Defining flashover for fire hazard calculation: Part II, Fire Safety Journal 38:613-622. doi:10.1016/S0379-7112(03)00027-4. 
Table 1. Fire and evacuation scenarios.

\begin{tabular}{|c|c|c|c|c|c|}
\hline $\begin{array}{c}\text { Fire } \\
\text { Scenario }\end{array}$ & $\begin{array}{c}\text { Evacuation } \\
\text { Scenario }\end{array}$ & Car separation & $\begin{array}{c}\text { Opening exits for } \\
\text { evacuation }\end{array}$ & $\begin{array}{c}\text { Population } \\
\text { load }\end{array}$ & Fire \\
\hline \multirow[t]{2}{*}{ S1 } & S1a & OWG & Side passenger doors & Full & \multirow{8}{*}{$\begin{array}{l}\text { Accidental } \\
\text { fire }\end{array}$} \\
\hline & S1b & OWG & Side passenger doors & Half & \\
\hline \multirow[t]{2}{*}{ S2 } & $\mathrm{S} 2 \mathrm{a}$ & ID & Side passenger doors & Full & \\
\hline & $\mathrm{S} 2 \mathrm{~b}$ & ID & Side passenger doors & Half & \\
\hline \multirow[t]{2}{*}{ S3 } & $\mathrm{S} 3 \mathrm{a}$ & OWG & End Cab doors & Full & \\
\hline & S3b & OWG & End Cab doors & Half & \\
\hline $\mathrm{S} 4 \mathrm{a}$ & $\mathrm{S} 4 \mathrm{a}$ & ID $^{\mathrm{a}}$ & End Cab doors & Full & \\
\hline S4b & S4b & ID $^{\mathrm{a}}$ & End Cab doors & Half & \\
\hline \multirow[t]{2}{*}{ S5 } & S5a & OWG & Side passenger doors & Full & \multirow{8}{*}{ Arson fire } \\
\hline & S5b & OWG & Side passenger doors & Half & \\
\hline \multirow[t]{2}{*}{ S6 } & S6a & ID & Side passenger doors & Full & \\
\hline & S6b & ID & Side passenger doors & Half & \\
\hline \multirow[t]{2}{*}{ S7 } & S7a & OWG & End Cab doors & Full & \\
\hline & S7b & OWG & End Cab doors & Half & \\
\hline S8a & S8a & ID $^{\mathrm{a}}$ & End Cab doors & Full & \\
\hline $\mathrm{S} 8 \mathrm{~b}$ & S8b & ID $^{\mathrm{a}}$ & End Cab doors & Half & \\
\hline
\end{tabular}

${ }^{a}$ The internal doors between cars are shut after the last survivor passes through the doorway. 
Table 2. Material properties [3].

\begin{tabular}{|l|c|c|c|c|}
\hline & Density $(\mathbf{k g} / \mathbf{m 3})$ & $\begin{array}{c}\text { Conductivity } \\
(\mathbf{W} / \mathbf{m K})\end{array}$ & $\begin{array}{c}\text { Specific Heat } \\
(\mathbf{J} / \mathbf{k g})\end{array}$ & $\begin{array}{c}\text { Ignition } \\
\text { temperature }\left({ }^{\mathbf{o}} \mathbf{C}\right)\end{array}$ \\
\hline FRP Polyester & 1795 & 0.295 & 1673.5 & 448 \\
\hline Styrene butadiene & 1478 & 0.19 & 1987.5 & 419 \\
\hline Wall panel & $548^{\mathrm{a}}$ & $0.11^{\mathrm{a}}$ & $2500^{\mathrm{a}}$ & 648 \\
\hline Glass & 1380 & 0.049 & 0.84 & -- \\
\hline
\end{tabular}

${ }^{\mathrm{a}}$ Data from [23]. 
Table 3. Time to close the internal car doors in the ID configuration scenarios with the end cab door open.

\begin{tabular}{|c|c|c|c|}
\hline Scenario & Between Cars 1-2 (s) & Between Cars 2-3 (s) & Between Cars 3-4 (s) \\
\hline S4a & $>1200$ & 420 & 300 \\
\hline S4b & 720 & 110 & 20 \\
\hline S8a & 300 & 120 & 60 \\
\hline S8b & 300 & 110 & 20 \\
\hline
\end{tabular}


Table 4. Average evacuation statistics for all scenarios.

\begin{tabular}{|c|c|c|c|c|c|c|}
\hline & Scenario & $\begin{array}{c}\text { Population } \\
\text { load }\end{array}$ & $\begin{array}{c}\text { Evacuation } \\
\text { time (s) }\end{array}$ & $\begin{array}{c}\text { Severe injuries } \\
\text { (survivors with } \\
\text { 1>FED > 0.5) }\end{array}$ & $\begin{array}{c}\text { Total No. of } \\
\text { incapacitations } \\
(\mathrm{FED}=1) / \%\end{array}$ & $\begin{array}{c}\text { No. of } \\
\text { incapacitations } \\
\text { within tunnel }\end{array}$ \\
\hline & Accidental Fire & & & & & \\
\hline \multirow{4}{*}{$\begin{array}{l}\text { Side } \\
\text { doors } \\
\text { open }\end{array}$} & S1a (OWG) & 715 & 743 & 59.0 & $73.7 / 10.3 \%$ & 3.6 \\
\hline & S2a (ID) & 715 & 666 & 6.8 & $49.1 / 7 \%$ & 1.6 \\
\hline & S1b (OWG) & 360 & 285 & $\mathbf{0}$ & $\mathbf{0}$ & $\mathbf{0}$ \\
\hline & S2b (ID) & 360 & 290 & 0 & 0 & 0 \\
\hline \multirow{5}{*}{$\begin{array}{l}\text { Only } \\
\text { end } \\
\text { cab } \\
\text { doors }\end{array}$} & S3a (OWG) & 715 & 1448 & 77.9 & $419.7 / 59 \%$ & 0.4 \\
\hline & S4a (ID) & 715 & 2356 & 67.0 & $185.6 / 26 \%$ & 0 \\
\hline & S3b (OWG) & 360 & 1419 & 71.6 & $67.6 / 19 \%$ & 0.4 \\
\hline & S4b (ID) & 360 & 1624 & 0 & 0 & 0 \\
\hline & Arson Fire & & & & & \\
\hline \multirow{4}{*}{$\begin{array}{l}\text { Side } \\
\text { doors } \\
\text { open }\end{array}$} & S5a (OWG) & 715 & 666 & 27.5 & $254.7 / 36 \%$ & 6.3 \\
\hline & S6a (ID) & 715 & 530 & 9.2 & $136.5 / 19 \%$ & 1.0 \\
\hline & S5b (OWG) & 360 & 432 & 12.3 & $32.8 / 9 \%$ & 3.8 \\
\hline & S6b (ID) & 360 & 310 & 6.0 & $29.2 / 8 \%$ & 1.3 \\
\hline \multirow{4}{*}{$\begin{array}{l}\text { Only } \\
\text { end } \\
\text { cab } \\
\text { doors }\end{array}$} & S7a (OWG) & 715 & 917 & 70.5 & $549.9 / 77 \%$ & 0.5 \\
\hline & S8a (ID) & 715 & 2364 & 140.0 & $171.0 / 24 \%$ & 0 \\
\hline & S7b (OWG) & 360 & 910 & 70.0 & $194.3 / 54 \%$ & 0.3 \\
\hline & S8b (ID) & 360 & 1549 & 12.7 & $22.0 / 6 \%$ & 0 \\
\hline
\end{tabular}


Table 5. Average evacuation statistics for agents moving between cars for scenarios with OWG configuration.

\begin{tabular}{|c|c|c|c|}
\hline Scenario & From Car 2 to Car 1 & From Car 3 to Car 2 & From Car 3 to Car 4 \\
\hline S1a & 13.6 & 24.0 & 10.5 \\
\hline S1b & 4 & 11 & 5 \\
\hline S5a & 13.7 & 6.3 & 4.4 \\
\hline S5b & 4 & 11 & 5.7 \\
\hline
\end{tabular}

